\title{
The narthex of the Church of the Nativity in Bethlehem: A non-linear finite element approach to predict the structural damage
}

\author{
Gabriele Milani ${ }^{\mathrm{a}, *}$, Marco Valente ${ }^{\mathrm{a}}$, Claudio Alessandri ${ }^{\mathrm{b}}$ \\ ${ }^{a}$ Department of Architecture, Built Environment and Construction Engineering, Politecnico di Milano, Piazza Leonardo da Vinci 32,20133 Milano, Italy \\ ${ }^{\mathrm{b}}$ Department of Engineering, University of Ferrara, Via G. Saragat 1, 44122 Ferrara, Italy
}

\section{A R T I C L E I N F O}

\section{Article history:}

Accepted 13 March 2017

Available online xxxx

\section{Keywords:}

Masonry

Church of the Nativity

Narthex

FE model

Non-linear dynamic analysis

Vault

\begin{abstract}
A B S T R A C T
The Church of the Nativity in Bethlehem has a narthex in the front that is as long as the façade of the Church and about six meters wide. Currently, the narthex is covered by five cross vaults, three of which in a dangerous state of decay, and it is internally divided by three walls perpendicular to the façade, which appears to be strongly rotated outwards with a maximum horizontal top displacement of about $40 \mathrm{~cm}$. Inside the central cross vault, the narthex has been heavily damaged and propped since the thirties of the last century. Numerous attempts have been made over the time to identify the causes of such damage. Some archival researches, in-situ inspections of the subsoil and detailed laser scanner surveys, which were carried out during the recent restoration works in the Church and in the narthex, allowed for gaining a deeper insight into the construction features of the cross vaults and for putting forward some hypotheses about the possible causes of damage. This paper provides a scientific validation of these hypotheses by means of finite element numerical simulations, which try to reproduce the seismic response of the Church and the deformation process of a three-dimensional simplified model of the narthex from an assumed initial configuration up to an ultimate state of damage, comparable with the current one. Such models are discretized by means of tetrahedron elements obeying a damage plasticity law that exhibits a softening behavior in both tension and compression. The numerical simulations carried out provide some results that fit reasonably with the actual deformed configuration of the narthex and can be considered as a useful tool for further insights.
\end{abstract}

(c) 2017 Elsevier Ltd. All rights reserved.

\section{Introduction}

Very little is known about the history of the transformations of the narthex of the Nativity Church since its construction. The narthex that we see now (or at least the narthex that we can imagine on the basis of the current volumes or the traces of some ancient and still visible openings on the walls) replaced a larger cloister in the second half of the VI century; such a cloister belonged to the previous Church, ordered by Queen Helena, mother of Emperor Constantine, in the IV century. From the outcomes of some archaeological excavations made by Hamilton [1] in the thirties of the last century and from the results of some subsequent studies [2,4], it was possible to go back to the original form of the narthex; differently from now, it was composed of a single volume, had a bigger central door flanked by two smaller side doors in both the principal walls and two windows placed symmetrically with respect to the front door, Fig. 1.

\footnotetext{
* Corresponding author.

E-mail address: milani@stru.polimi.it (G. Milani).
}

From some traces found in the walls during the restoration works, still in progress, it was possible to deduce that the original roof of the narthex was made of timber, with a single pitch, as in almost all early Christian and Byzantine basilicas with narthex. The typology of the wooden roof is still unclear, although the traces left on the walls suggest that it consisted of a series of simply supported beams having the same slope as the roof; certainly it was a light roof. Over the centuries, especially during the Middle Ages, the Church increasingly took on the appearance of a fortress equipping itself with walls and towers for defense. Some traces of these additions are visible today even in the narthex, in particular in a small protective parapet above the façade and in two thick interior walls, perpendicular to the façade, probably the base of two outer towers, Figs. 2 and 3. Maybe, in order to allow these transformations for protective purposes or as a consequence of some destructive earthquakes, the original timber roof was replaced by a system of masonry cross vaults and some openings were infilled or reduced in size. The two thicker inner walls are made of low quality masonry, surely lower than the one of the external walls, and they are simply adhering to the façade walls of both narthex and Church without any effective connection. 


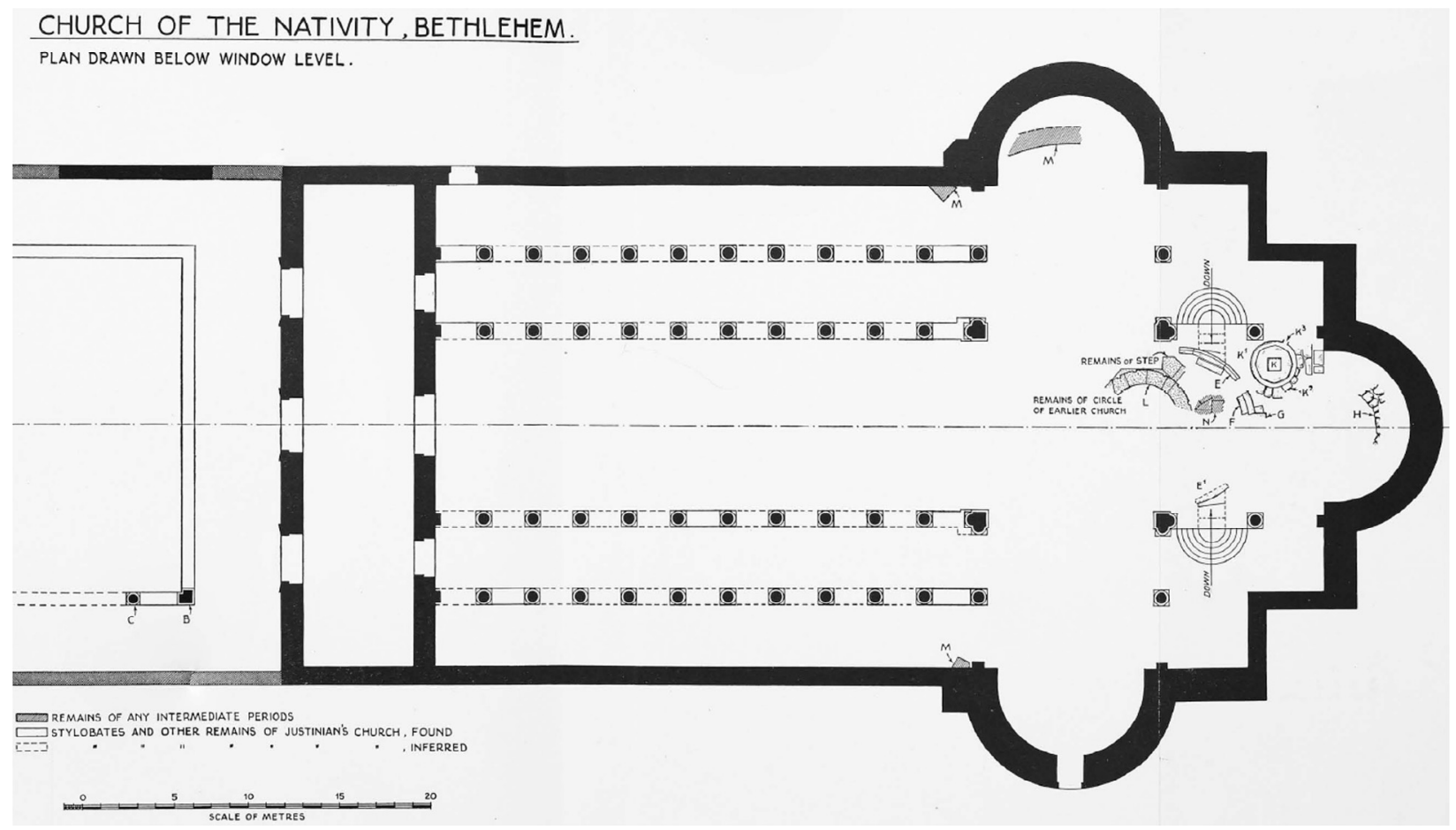

Fig. 1. Original narthex of the Church of the Nativity.

Also the vaults, made of irregular and roughly cut stones, are connected to the façade walls only in correspondence with the corbels at the base of the arches and for a height of about 1.1-1.3 m. Instead, such vaults are well connected with each other in the EastWest direction (the longitudinal direction of the Church) by means of arches, orthogonal to the façades and built with greater and more regular stones. Moreover, such stones have two different lengths and they are assembled in such a way that the longer stone and the shorter one are always alternate, so as to allow for a greater connection between arches and vaults. Even the diagonal arches of the vaults are made of quite regular stones, although not so regular as the ones of the arches mentioned before. The thickness of the vaults is not constant everywhere and it varies between 35 and $40 \mathrm{~cm}$. Before starting the restoration, the space between the existing external paving and the extrados of the vaults was filled with sand and remains of a medieval paving. Some inspections made on site have shown that the walls of the narthex continue downwards with a constant thickness up to a depth of $94 \mathrm{~cm}$ from the floor; then they have an enlargement of $20 \mathrm{~cm}$ on each side up to a depth of $141 \mathrm{~cm}$ and continue with a compact layer of stones and mortar for other $150-165 \mathrm{~cm}$ before reaching the bedrock. The two side walls of the narthex (North and South sides) are $1 \mathrm{~m}$ thick and have an inner core of undefined thickness; the façade wall, like the façade of the Church, is 1.15 m thick, made of regular stones and with a limited or null inner core. The narthex is now connected to the monasteries of the Franciscans Friars (North) and of the Armenian religious community (South), Fig. 2; these monks, together with the Greek Orthodox ones, manage the activities in the Church according to the current status quo. On the external front, towards the square, there is a big buttress probably built after the XVI century: in fact, some drawings made by Amico [3] and dating back to 1609 show the façade of the narthex still without the buttress, Fig. 4.

The present paper, which is an extension and a thorough revision of that presented during CC2015 congress [5], Fifteenth International Conference on Civil, Structural and Environmental Engineering Computing, held in Prague, Czech Republic 1-4
September 2015, presents and discusses a wide set of numerical results validating the aforementioned hypotheses of structural damage of the narthex. The results are obtained by means of advanced numerical finite element (FE) simulations, which include non-linear dynamic analyses. Such advanced FE approaches try to reproduce the deformation process on detailed three-dimensional models of both the whole church and the isolated narthex. The FE models consist of tetrahedron elements and masonry is treated as a homogeneous macroscopic material obeying a damage plasticity law, which exhibits a softening behavior in both tension and compression. The numerical simulations carried out provide several results that seem to fit reasonably with the actual deformed configuration and can be considered as a useful tool for further insights, including rehabilitation, strengthening and seismic vulnerability reduction.

\section{State of the structural damage and possible causes}

Nowadays the structure of the narthex is strongly deformed [6]. The façade wall exhibits a rotation towards the square more pronounced in the middle of its length and starting approximately from the architrave of the Humility door, about one meter above the ground. As a consequence of such a rotation, the façade wall has undergone a maximum horizontal displacement at the top, approximately in the middle of the wall, equal to about $40 \mathrm{~cm}$ measured at the base of the parapet. It is a very high value when compared with the height of the wall, about $8.7 \mathrm{~m}$. If any fractures occurred in the past, they were closed by local interventions of cleaning and consolidation made over the centuries. The fact that they have not re-opened ever since shows that the damage evolution is now over and that it was probably over even when the external buttress, now still perfectly vertical, was added. The façade of the Church, opposite to the one of the narthex, exhibits a slight out-of-plane deformation, which starts from the roof of the narthex and achieves $10 \mathrm{~cm}$ at the top of the tympanum [6]. As a consequence of the rotation of the narthex façade, the three central vaults, and in particular the one in the middle, underwent 


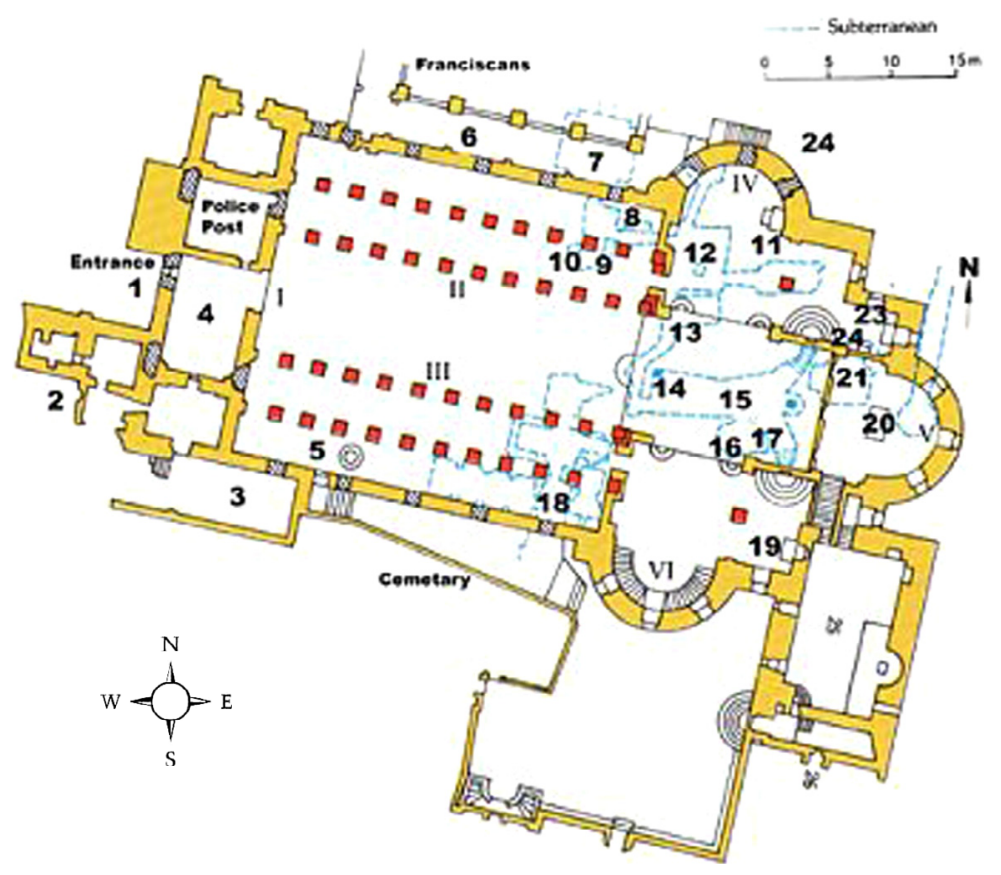

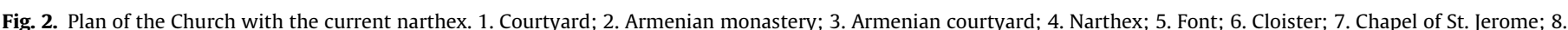

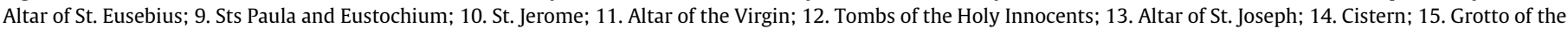

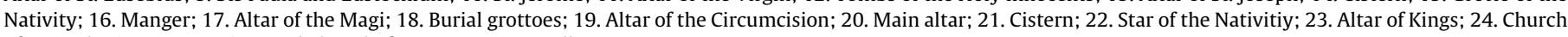
of St. Catherine; 25. Sacristy and chapel of St. George; 26. Bell tower.

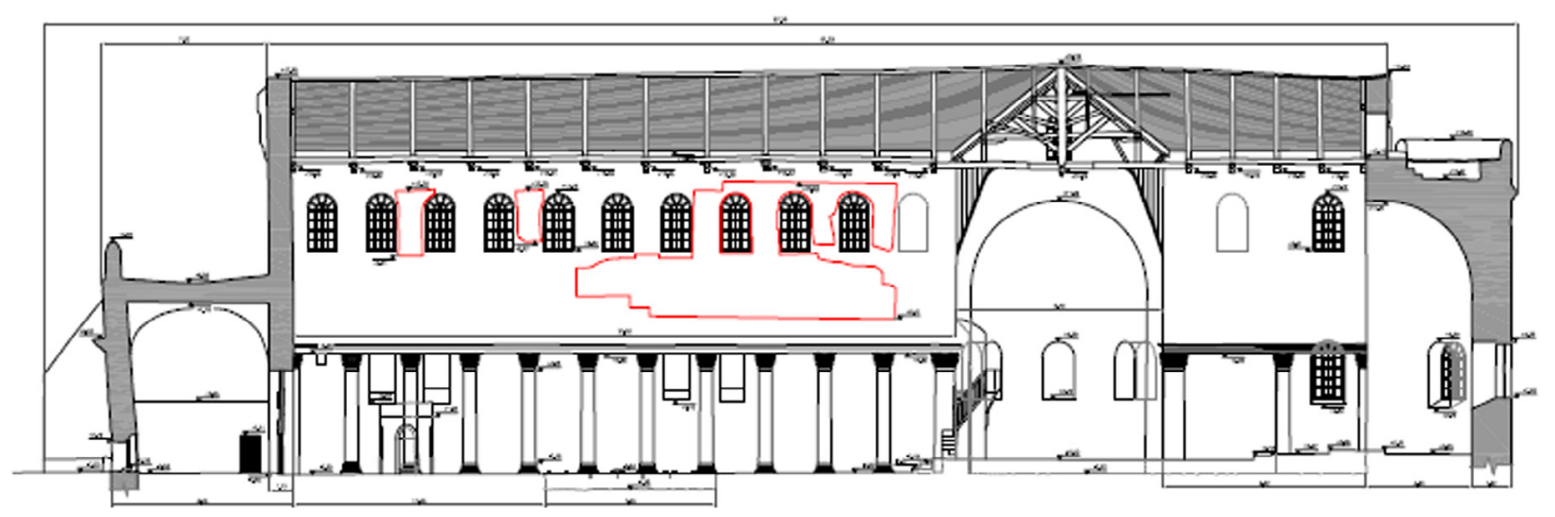

Fig. 3. Longitudinal section of the Church.

vertical displacements downwards in the central zones, detachments from the façade walls and both extrados and intrados cracks. Especially the central vault, propped since the thirties of the last century, exhibits detachments equal to $17-19 \mathrm{~cm}$ from the narthex façade and $10-11 \mathrm{~cm}$ from the Church façade, Fig. 5a. Moreover, large cracks, parallel to the façades, are visible at the extrados, Fig. 5b.

The arches connecting the vaults to each other (in the East West direction) and also the ones along the diagonal planes of the vaults are strongly deformed. The causes of these damages have never been clarified. The replacement of the original wooden roof with a set of thrusting masonry vaults probably gave a significant contribution to the rotation of the façade towards the square. It is believed, however, that such thrusts alone were not able to cause maximum horizontal displacements as large as those measured. Therefore, since Bethlehem is in a seismic area that over the centuries underwent several earthquakes, some of which even severe, it is very probable that a single seismic event, or a series of seismic events, occurred before the construction of the buttress, has been among the main causes of damage. The external buttress, added in the last centuries, as mentioned above, shows no sign of rotation and no differential vertical displacement.

The aim of this work is to explain, through proper numerical simulations, if a seismic event, together with the thrust of the vaults, may have caused the damage in the vault system and the present out-of-plane deformation of the narthex façade. To this purpose, a 3D finite element model of the entire Church was built and analyzed by using the commercial software ABAQUS [7]. The model reproduces a configuration of the church as is possible to suppose at the beginning of the Crusader period, immediately after the replacement of the original wooden roof with the present vault system. Such a model is initially assumed as not deformed, without the external buttress, added only after the XVI century, without the current connections with the monasteries on the North and South sides, also added later, without the thickest internal walls which, even if supposed coeval with the vaults, are simply in adherence with the two façades and therefore not interacting with them. The openings in the narthex façade are the current ones: the access 


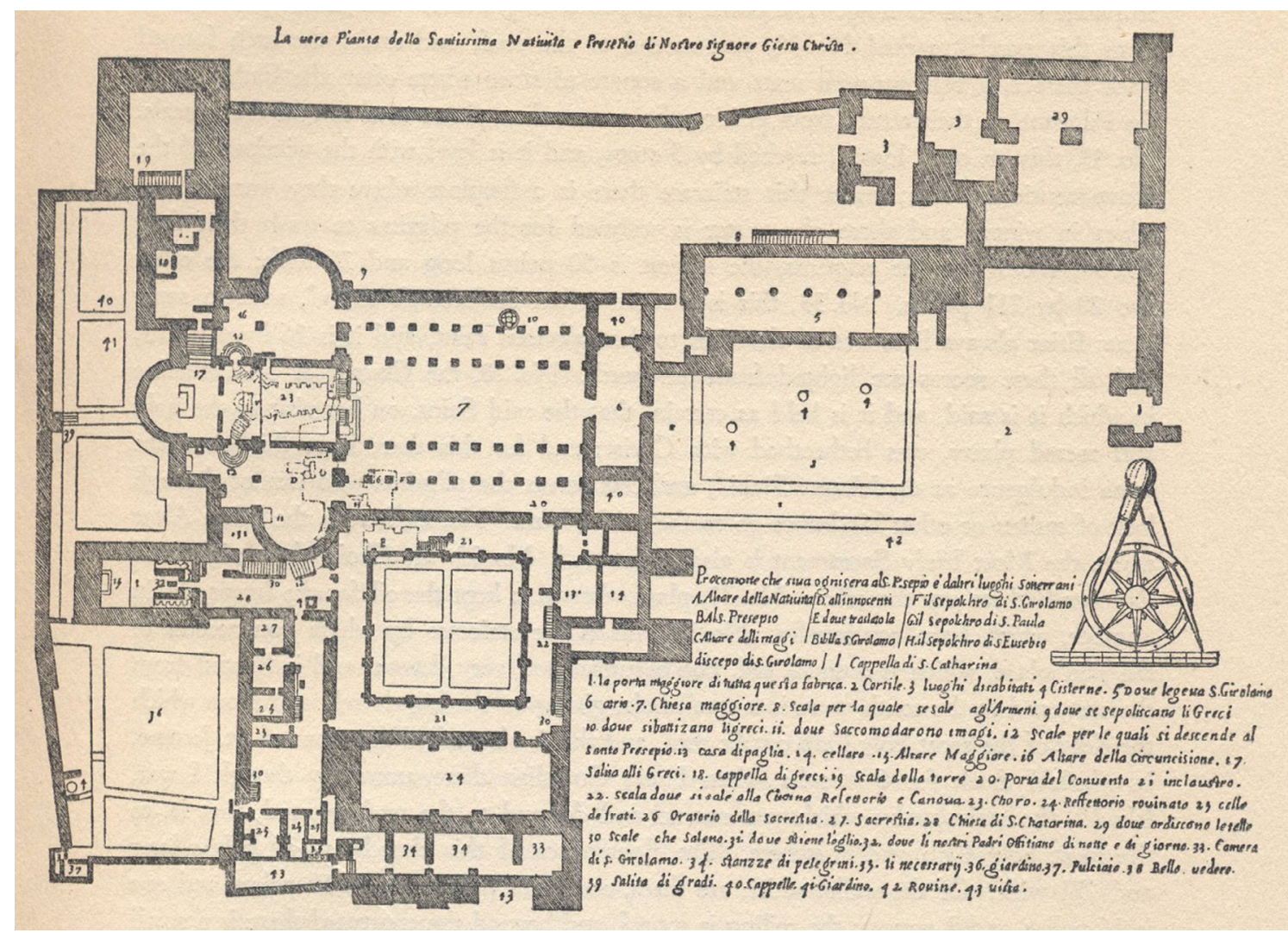

Fig. 4. Plan of the Nativity Church (1609).

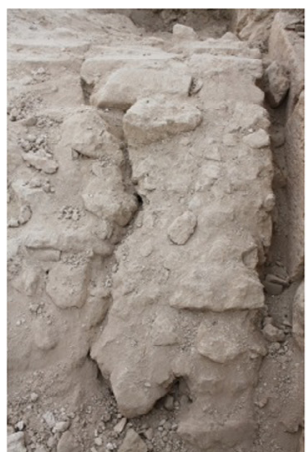

(a)

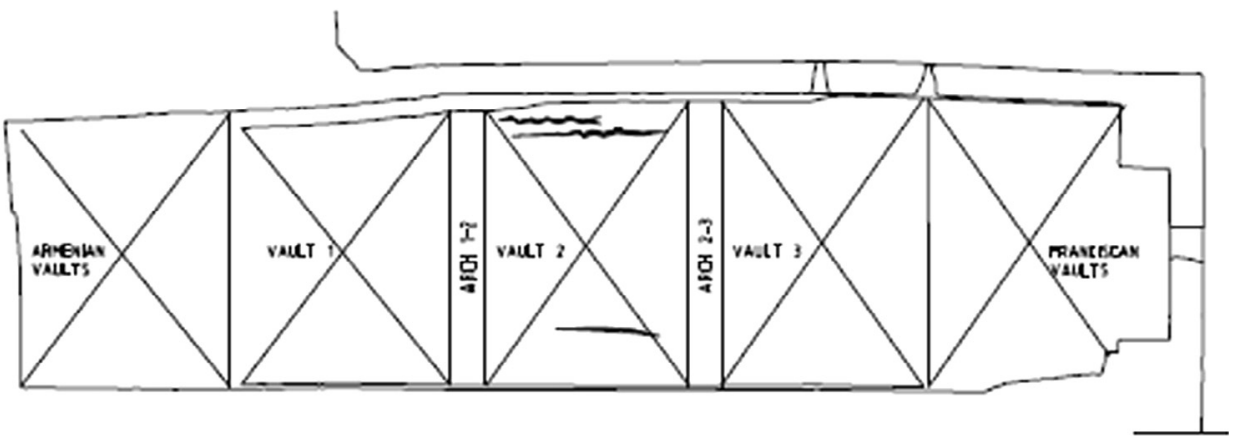

(b)

Fig. 5. (a) Detachments from the wall, (b) cracks at the extrados of the central vault

door (the Humility door) and two small windows. The original openings of Justinian's time are still not reproducible because of the lack of reliable survey data. The side walls of the narthex are supposed to be connected to the longitudinal external walls of the Church. The vaults are connected to the surroundings walls and have thicknesses and heights with constant values, averaged over the real ones that show some differences among them. They are also connected to each other in the East - West direction by means of arches similar to the real ones, Fig. 5b, and clamped to both the façades. Moreover, the façade of the Church is connected to the orthogonal walls of the nave and aisles. Fig. 6 offers a view of the masonry cross vault system in the model of the narthex.
It is worth noting that a three-dimensional structural analysis of the entire Church is significant when a good level of interlocking among the structural elements is guaranteed. If such connections are not reliable, as in the case of the Church of the Nativity, it is advisable to perform numerical analyses on smaller portions that may be affected by local collapse mechanisms.

Moreover, serious damage observed in some masonry walls from in-situ survey was caused by the rainwater infiltration due to a lack of appropriate maintenance of the roof of the church over an extended period of time. Such a damage is not taken into account in the model and the predicted damage obtained through the numerical simulations is due to seismic excitations only. 


\section{Numerical simulations and constitutive model for masonry}

With the aim of reproducing the actual state of damage on the church, it was chosen to study the effects of a possible earthquake through non-linear dynamic analyses by applying spectrum compatible acceleration time-histories at the base of the structure. Such a method of analysis is very time consuming, but it is much more accurate and reliable than other approaches for its capability to identify in- and out-of-plane displacements, as well as local and global failure mechanisms. Different three-dimensional finite element models of both the church and the narthex are implemented in ABAQUS [7], taking into consideration geometrical (large dis-

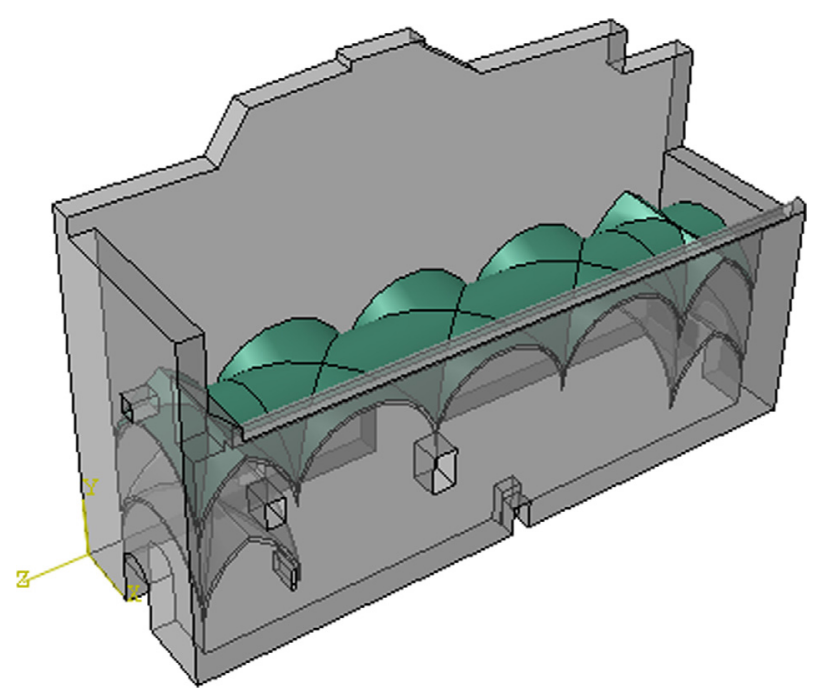

Fig. 6. The system of masonry cross vaults in the model of the narthex.
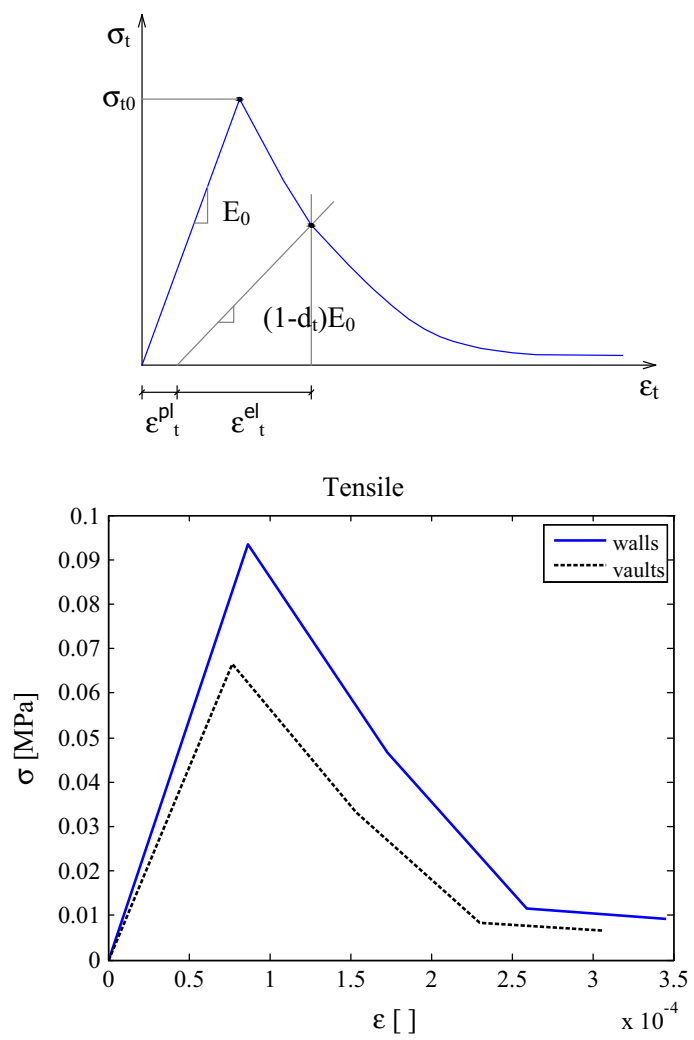

placement effects) and material non-linearity (elastic-plastic damaging behavior of the masonry material). Despite some general drawbacks regarding non-linear dynamic analyses, the use of sophisticated 3D models requires a relatively reasonable computational effort on sufficiently powerful workstations, if the discretizations are not excessively refined and the material models do not exhibit strong softening.

On the other hand, recent advanced studies on masonry monumental buildings, see for instance [8-22], seem to indicate that, to have an insight into the structural behavior of such complex structures, a broad blend of different analyses should be used, ranging from standard eigen-frequency ones, passing through kinematic limit and pushover analyses, and ending with non-linear dynamic analyses. Such a comprehensive numerical procedure seems also suggested and confirmed by European and Italian codes [23-26]. In particular, Italian Guidelines for the built heritage [26] specify that such analyses can be conducted using finite element models and considering suitable constitutive models. Such models should be capable of reproducing the typical strength and stiffness degradation exhibited by the masonry material in the inelastic range. Whilst preliminary eigen-frequency and limit analyses have been carried out by the authors to progressively study the behavior of both the Church and the narthex under horizontal loads, the results are not reported here for the sake of conciseness. Here, only the results obtained by means of the non-linear dynamic analyses are discussed, because they probably provide the structural scenario that is the closest to the actual behavior of the structure under possible earthquake sequences occurred in the past.

It is well-known that the numerical modelling and dynamic response of masonry structures are characterized by a great complexity because of the composite nature of materials and the non-linearity involved. Furthermore, masonry is generally orthotropic [27-30] and suitable homogenization procedures [28-30]
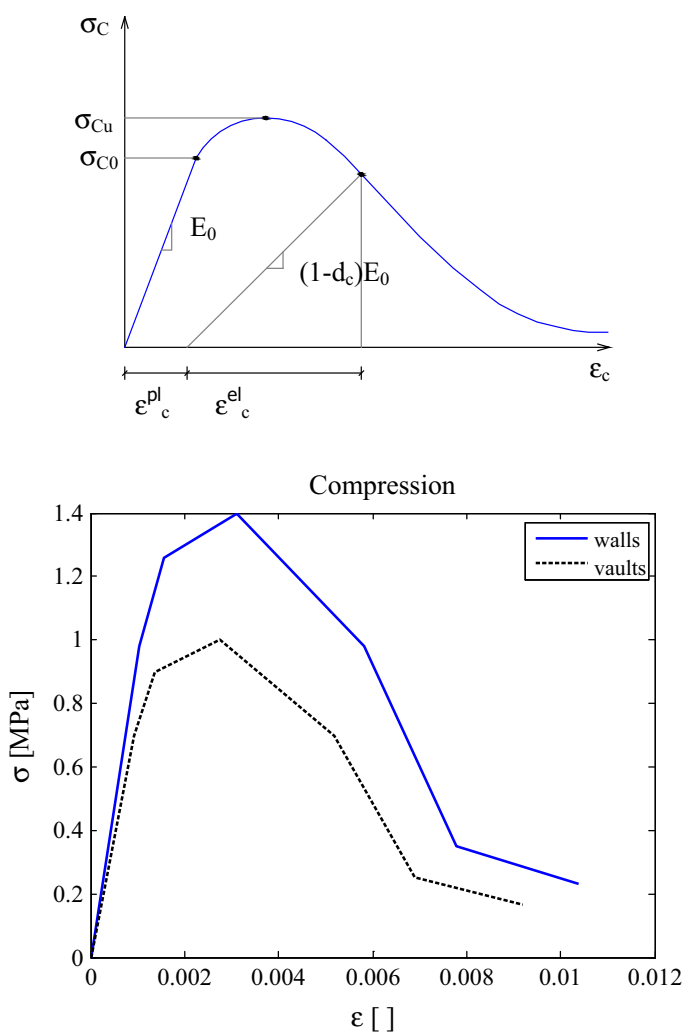

Fig. 7. Tensile and compression mono-axial inelastic curves for masonry adopted in the numerical simulations. 
should be used to cope with this issue. However, considering the well-known great computational effort required by the use of both micro-modelling and homogenization at large scale, and considering that for irregular masonry texture the orthotropy ratio is close to 1 , isotropic macro-models are adopted for masonry. The reason for adopting an isotropic material stands in the impossibility to evaluate many parameters necessary for anisotropic materials in the inelastic range, in the absence of ad-hoc experimental characterizations. Moreover, it is worth noting that commercial codes rarely make available to users anisotropic mechanical models suitable to describe masonry in the non-linear range.

In this study the non-linear behavior of masonry is modelled through the Concrete Damage Plasticity (CDP) model presented by Lubliner [31] and then modified by Lee and Fenves [32], which is available within the ABAQUS software. Although originally conceived to describe the non-linear behavior of concrete, the model can be used for masonry through a proper adaptation of the main parameters $[18,33]$. The model is based on the assumption of a scalar isotropic damage with distinct damage parameters in tension and compression and it is particularly suitable for the analysis of structures subjected to cyclic and dynamics loads. A different elastic-plastic behavior in tension and compression can be taken into account, as illustrated in Fig. 7.

In tension the stress-strain response follows a linear-elastic relationship until the peak stress $\sigma_{t 0}$ is reached. Then, microcracks start to propagate in the material, a phenomenon which is macroscopically represented by softening in the stress-strain relationship.

Under axial compression, the response is nearly linear up to the value of the yield stress $\sigma_{c 0}$. After the yield stress, the response is typically characterized by hardening, which anticipates compression crushing, represented by a softening branch beyond the peak stress $\sigma_{c u}$.

Damage variables in tension and compression are defined by means of the following standard relationships:

$$
\begin{aligned}
& \sigma_{t}=\left(1-d_{t}\right) E_{0}\left(\varepsilon_{t}-\varepsilon_{t}^{p l}\right) \\
& \sigma_{c}=\left(1-d_{c}\right) E_{0}\left(\varepsilon_{c}-\varepsilon_{c}^{p l}\right)
\end{aligned}
$$

where $\sigma_{t}\left(\sigma_{c}\right)$ is the mono-axial tensile (compressive) stress, $E_{0}$ is the initial elastic modulus, $\varepsilon_{t}\left(\varepsilon_{c}\right)$ is the total strain in tension (compression), $\varepsilon_{t}^{p l}\left(\varepsilon_{c}^{p l}\right)$ is the equivalent plastic strain in tension (compression). The elastic modulus gradually degrades every time the strain reaches a critical value. The damage variables $d_{c}$ and $d_{t}$ have been set equal to 0.95 at the strain corresponding to the residual uniaxial stress value in tension and compression, respectively. The elastic stiffness assumes a value equal to $5 \%$ of the initial one in correspondence with such strain values.

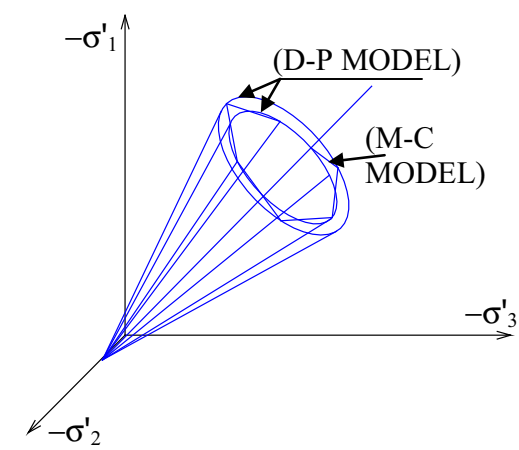

Mesh objectivity in the softening branch passes through an indirect definition of the fracture energy, which is fully documented in the ABAQUS User's Guide [7]. Having so derived the fracture energy, the model is local and regularization occurs scaling the fracture energies by means of the equivalent length $\bar{h}$ defined as $\bar{h}=\alpha_{h} \sqrt{V_{e}}=\alpha_{h}\left(\sum_{\rho=1}^{n_{\rho}} \sum_{\xi=1}^{n_{\xi}} \sum_{\eta=1}^{n_{\eta}} \operatorname{det} J w_{\rho} w_{\xi} w_{\eta}\right)$ where $w$ are the weight factors of the Gaussian integration scheme, $J$ the Jacobian of the transformation, $V_{e}$ the element area and $\alpha_{h}$ a modification factor that depends on the typology of the element used.

To describe the multi-dimensional behavior in the inelastic range, masonry is assumed obeying a Drucker-Prager strength criterion with non-associated flow rule, Fig. 8. A parameter $K_{c}=0.667$, applied to the analytical expression for the Drucker-Prager surface in the principal stress space, allows distorting the surface, making it more similar to that of the Mohr-Coulomb criterion.

To avoid numerical convergence issues, the tip of the conical domain of the Drucker-Prager strength domain is smoothed with a function having hyperbolic shape. ABAQUS code allows ruling smoothing by means of the so-called eccentricity parameter, which represents the length of the segment between the points of intersection of the cone and of the hyperbola with the $p$ axis in the $p-q$ space, see Fig. 9. A value equal to 0.1 is adopted for the eccentricity parameter. Smaller values may cause convergence problems when the material is subjected to low confining pressures because of the very tight curvature [7].

A value equal to $10^{\circ}$ is assumed for the dilatancy angle, in agreement with experimental evidences available in the literature [34] and previous numerical models recently adopted in different case studies $[18,35]$.

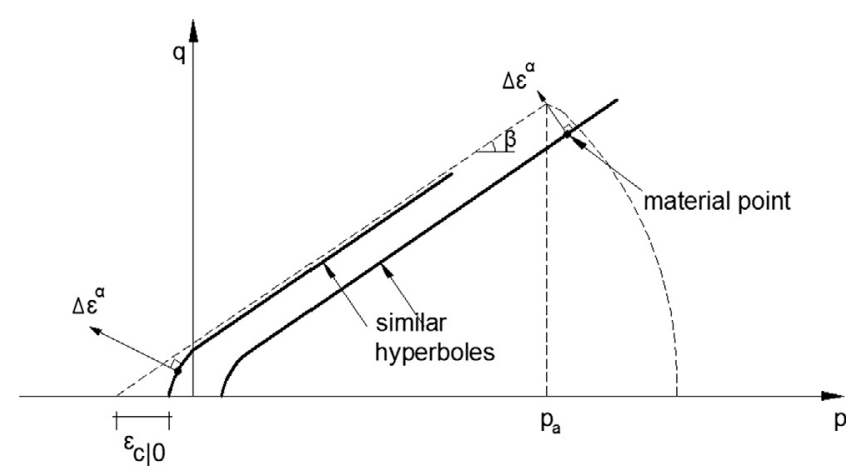

Fig. 9. Smoothed Druker-Prager failure criterion adopted in the numerical simulations, p-q plane.

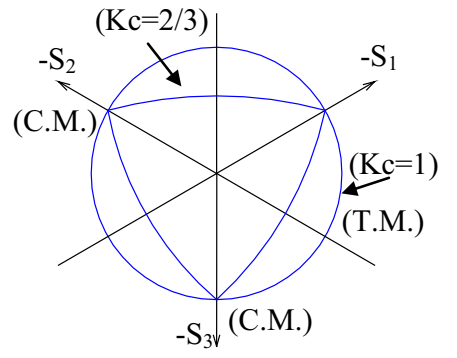

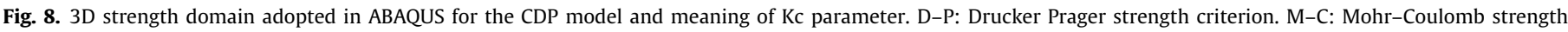
criterion. C.M.: compressive meridian. T.M.: tensile meridian. 
Table 1

Values of the main parameters of the Concrete Damage Plasticity model adopted for masonry in the numerical simulations.

\begin{tabular}{ll}
\hline Parameter & Value \\
\hline Dilatancy angle $\left(^{\circ}\right)$ & 10 \\
Eccentricity & 0.1 \\
$\mathrm{f}_{\text {bo }} / \mathrm{f}_{\text {co }}$ & 1.16 \\
$\mathrm{Kc}$ & 0.667 \\
Viscosity parameter & 0.002 \\
\hline
\end{tabular}

A suitable model should take into account the ratio between the ultimate compression strength in biaxial stress states and in uniaxial conditions. Such a ratio $\mathrm{f}_{\mathrm{bo}} / \mathrm{f}_{\mathrm{co}}$, which exhibits some similarities between concrete and masonry, is reasonably set equal to 1.16.

Some convergence difficulties can arise in numerical analyses when material models exhibiting softening behavior and stiffness degradation are used. The viscosity parameter $\lambda$, which is introduced in the model in order to obtain a visco-plastic regularization of the constitutive equations and allows overcoming convergence difficulties, is assumed equal to 0.002 . Small values of the viscosity parameter help to improve the rate of convergence in the softening branch without significantly compromising the results.

A summary of the values of the main parameters adopted in the non-linear dynamic analyses are reported in Table 1.

The issue of the mechanical properties to adopt for masonry results particularly difficult, especially in the absence of ad hoc experimental campaigns and specific indications by local building codes. Consequently, due to the lack of precise experimental data and specific indications, in this study it was chosen to refer to what is stated by Italian Code for existing masonry buildings.

According to Italian Code NTC 2008 [24] and subsequent Explicative Notes [25], the main mechanical properties assumed for masonry material depend on the so-called knowledge level LC, which is related to the so-called Confidence Factor FC. There are three LCs, labeled from 1 to 3, related to the knowledge level about the mechanical and geometrical properties of the structure. The knowledge level LC3 is the maximum, whereas LC1 is the lowest. For the cases at hand, a LC1 level is assumed in the absence of specific in-situ test results.
The values adopted for material parameters are taken in agreement with Table C8A.2.1 of the Explicative Notes [25], assuming a masonry typology with poor mechanical properties. Two different materials have been taken into account: one for the masonry of the vaults and another for the remaining part (walls) of the Church. In particular, "masonry blocks of soft stone" and "disordered masonry stones" (according to Italian Code) are assumed as the material of the walls and of the vaults, respectively. With the lowest knowledge level LC1, Italian Code requires to select, in Table C8A.2.1, the lower bound values for strength and the average values between lower and upper bound for elastic moduli.

The compressive and tensile strength of masonry was set equal to $\sigma_{\mathrm{cu}}=1.4 \mathrm{MPa}$ and $\sigma_{\mathrm{to}}=0.093 \mathrm{MPa}$, respectively, obtaining a ratio between the tensile and compressive strength equal to 0.066; the unit weight and the elastic modulus were assumed equal to $\mathrm{w}=16 \mathrm{kN} / \mathrm{m}^{3}$ and $\mathrm{E}=1080 \mathrm{MPa}$, respectively. As regards the masonry of the vaults, the compressive and tensile strength was set equal to $\sigma_{\mathrm{cu}}=1 \mathrm{MPa}$ and $\sigma_{\mathrm{to}}=0.066 \mathrm{MPa}$, respectively; the elastic modulus was assumed equal to $\mathrm{E}=870 \mathrm{MPa}$.

The final inelastic stress-strain relationships adopted in the constitutive model of masonry are reported in Fig. 7 for the tensile and compression mono-axial curves.

\section{Non-linear dynamic analyses of the Church}

A detailed three-dimensional finite element model of the entire Church was developed in ABAQUS software code, Fig. 10, with the aim of investigating the seismic behavior of the structure through non-linear dynamic analyses. A finite element discretization, based on four node tetrahedral elements presenting an average size of $0.40 \mathrm{~m}$, was adopted. The total number of elements of the model

Table 2

Main mechanical properties of the different materials of the finite element model.

\begin{tabular}{llll}
\hline & E [MPa] & $v$ & $\mathrm{w}\left[\mathrm{kN} / \mathrm{m}^{3}\right]$ \\
\hline Masonry (walls) & 1080 & 0.2 & 16 \\
Masonry (vaults) & 870 & 0.2 & 16 \\
Marble & 80,000 & 0.2 & 20 \\
Wood & 12,500 & 0.15 & 7.05 \\
\hline
\end{tabular}
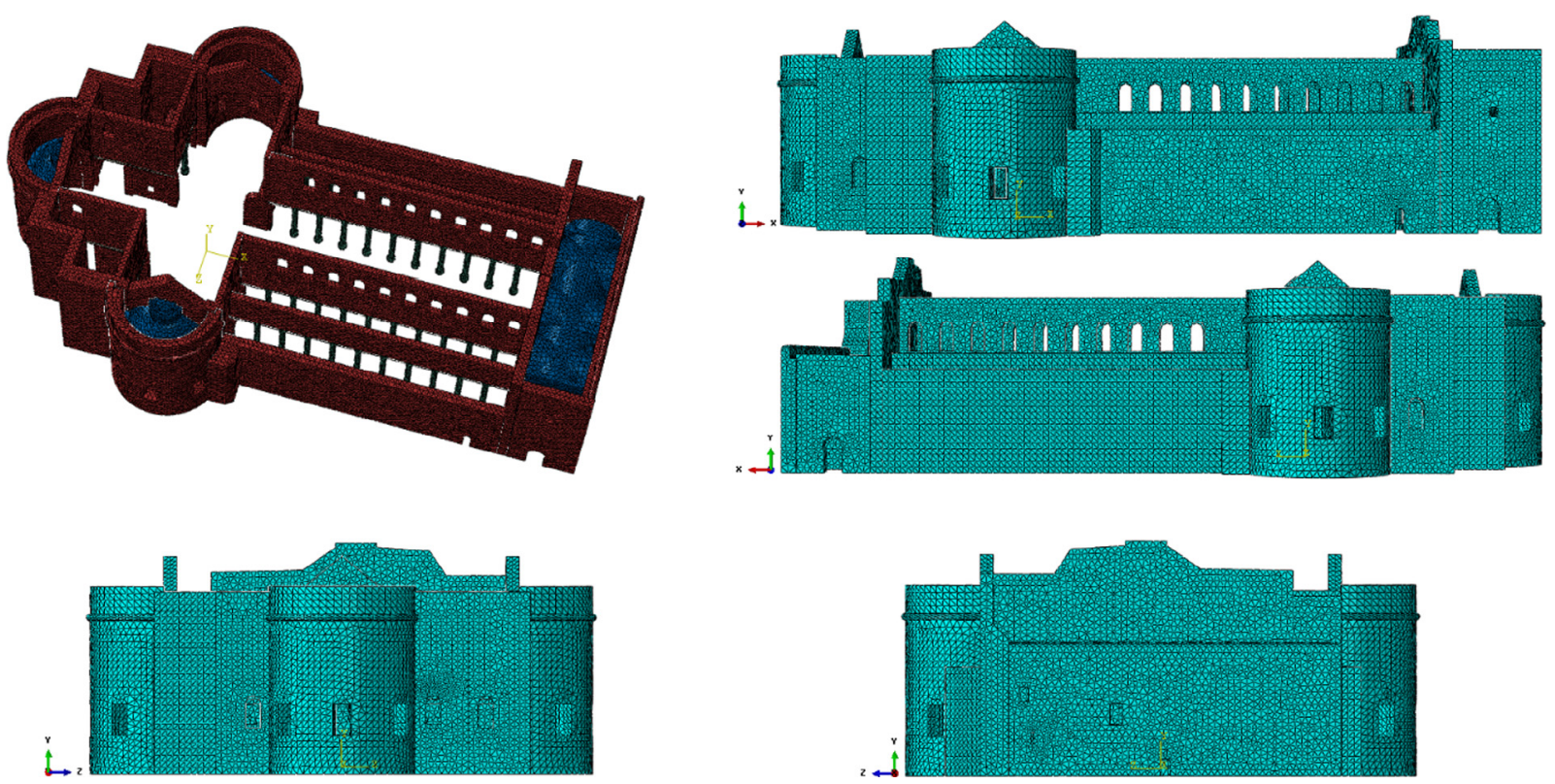

Fig. 10. Finite element model of the entire Church of the Nativity.

Please cite this article in press as: Milani G et al. The narthex of the Church of the Nativity in Bethlehem: A non-linear finite element approach to predict the structural damage. Comput Struct (2017), http://dx.doi.org/10.1016/j.compstruc.2017.03.010 

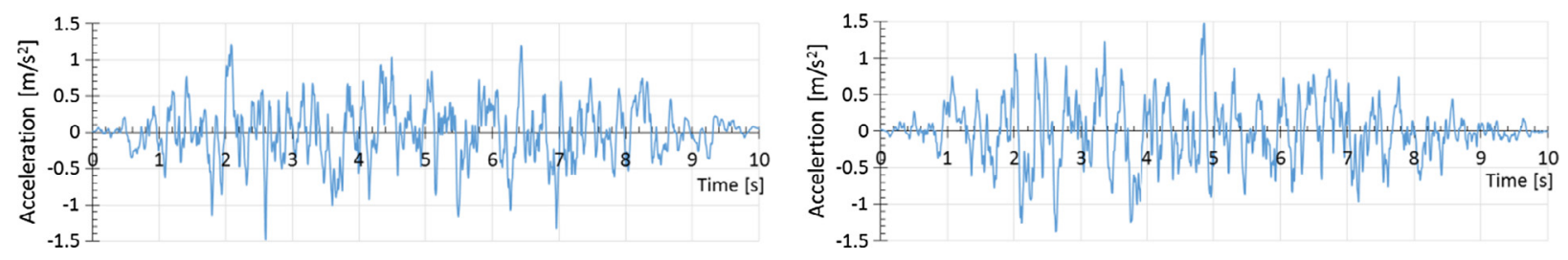

Fig. 11. Artificial accelerograms used for the bidirectional non-linear dynamic analyses of the Church.

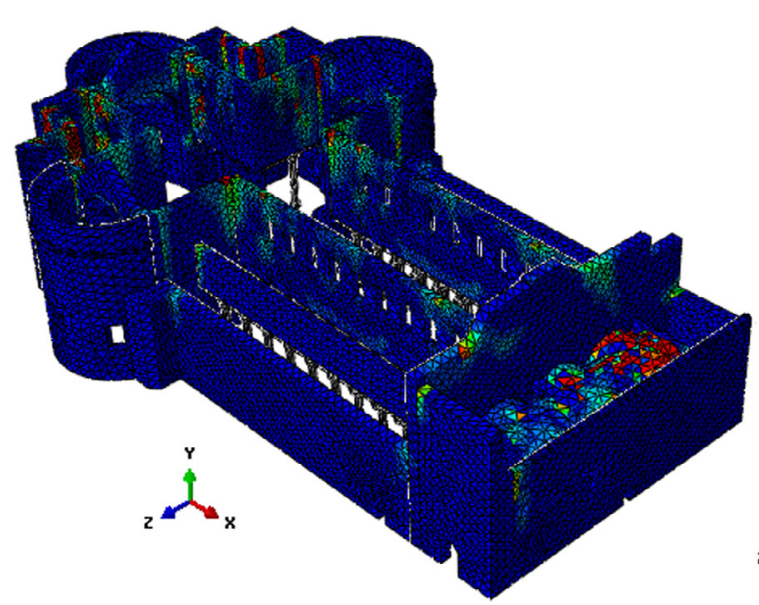

DAMAGET
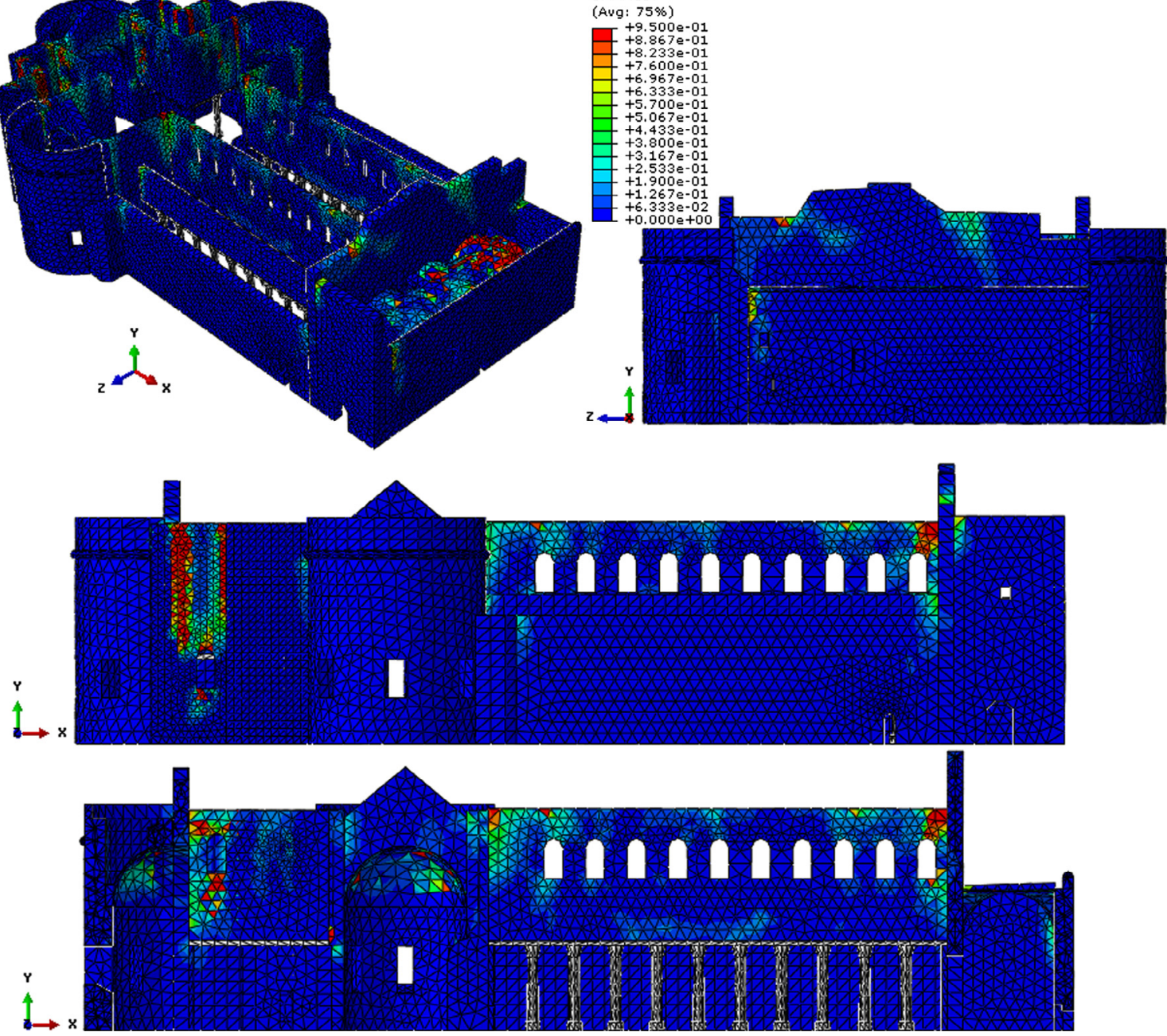

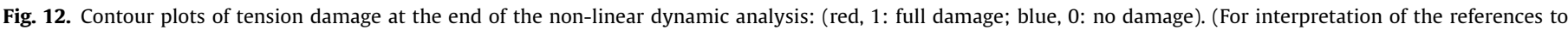
colour in this figure legend, the reader is referred to the web version of this article.)

was equal to 131,551 . In particular, the mesh was refined near the regions where the main failure mechanisms were likely to start. Since not negligible out-of-plane displacements may occur during a seismic event, large displacement effects were considered. Perfect connections were assumed between perpendicular walls. The wooden roof was not modelled and only vertical loads transferred by the roof to masonry walls were introduced in the models.

The main parameters (Young's modulus E, Poisson's ratio $v$ and unit weight $\mathrm{w}$ ) listed in Table 2 were used for the different materials of the Church.

The bidirectional non-linear dynamic analyses were performed by using artificial accelerograms generated through the software code SIMQKE. In this study the Church was subjected to spectrum compatible accelerograms corresponding to a peak ground acceleration equal to $\mathrm{a}_{\mathrm{g}}=0.15 \mathrm{~g}$ according to Eurocode 8 . The region where the Church is located (without specific seismic norms provided by Palestine state, Eurocode 8 is assumed as reference) can be considered as a medium-intensity seismic area with $\mathrm{a}_{\mathrm{g}}=0.15 \mathrm{~g}$, where $\mathrm{a}_{\mathrm{g}}$ is the maximum horizontal acceleration occurring in the area, with a $10 \%$ of probability of exceeding this value over 50 years. Due to the complexity of the model and the high computational time required by the non-linear dynamic analyses, the duration of the accelerograms was set equal to $10 \mathrm{~s}$. The artificial accelerograms used for the bidirectional non-linear dynamic analyses are shown in Fig. 11. It is worth mentioning that artificial accelerograms are usually characterized by a large number of cycles and therefore such records may generally lead to conservative response quantities and damage distribution.

In Figs. 12 and 13 the contour plots of tension and compression damage (red color is associated to full (1) damage and blue color to 


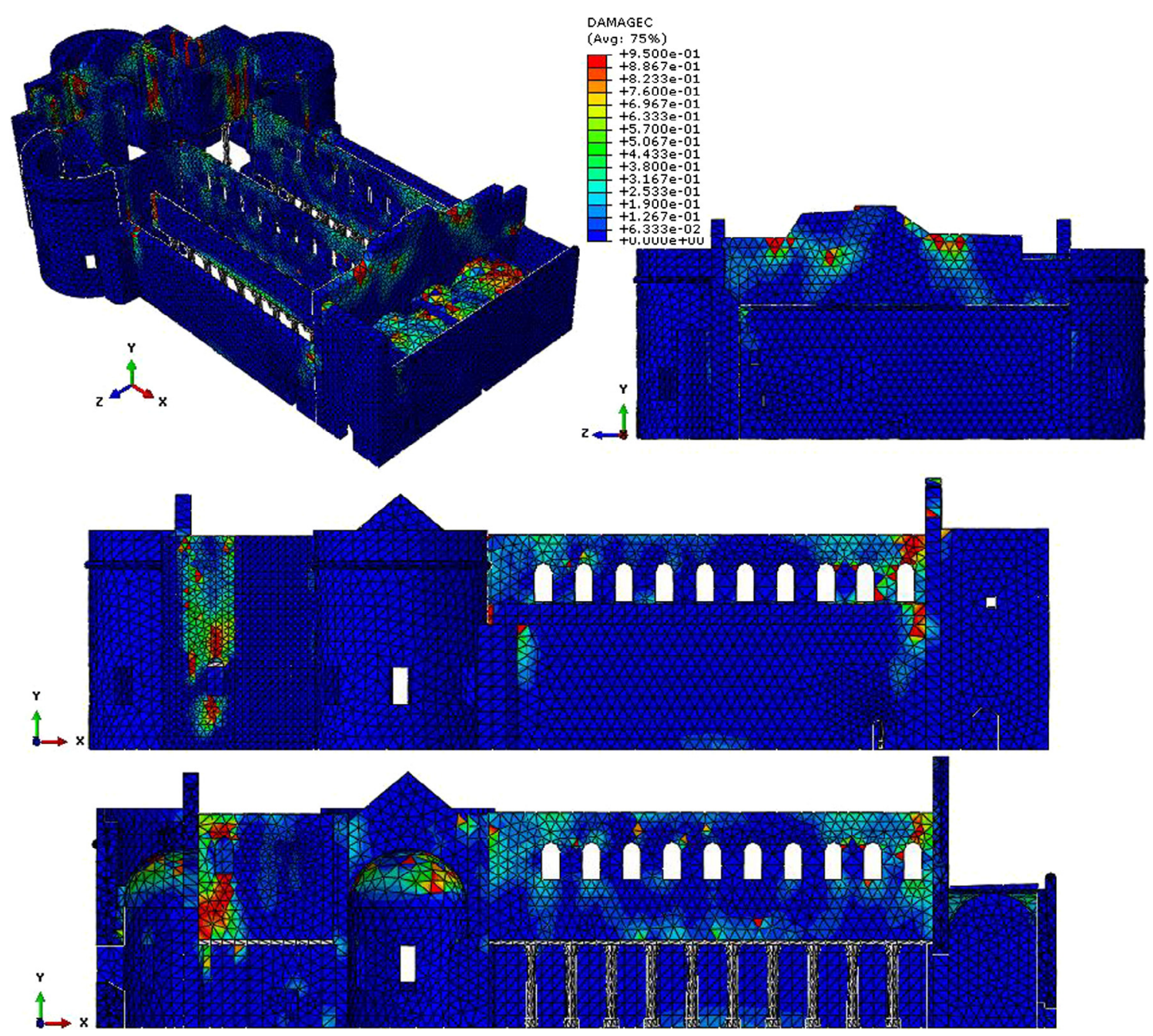

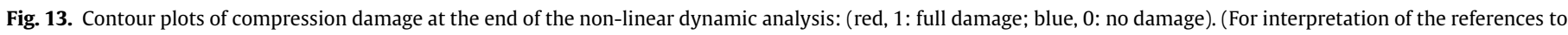
colour in this figure legend, the reader is referred to the web version of this article.)

zero (0) damage), respectively, are shown from different points of view at the end of the numerical simulation. From an overall analysis of the numerical results, it is possible to notice that the Church exhibits significant damage under the seismic excitation expected in that region. It is evident that damage spreads very quickly in the vault system, in the semi-domes and near the interlockings of the orthogonal walls. The damage in the vaults starts in the lateral right corner and then propagates towards the middle.

In fact, the crack pattern surveyed before starting the restoration works and visible through the XIX century plaster [6] shows some vertical cracks at the intersection of the orthogonal walls, especially those of the nave and the transept, Fig. 14.

Moreover, it was known [4] that all the Eastern area, including part of the nave, the transept and the apse, had undergone significant modifications over the centuries due to events not documented historically, but that might be also related to earthquakes. Traces of such modifications can be found in the buffered windows of the upper level in correspondence with the corners between transept and apse and between transept and nave, Figs. 15 and 16.

Other visible traces can be found in two opposite walls of the North and South corners in the Eastern part, where a clear change in both the type and quality of the stones, due to a re-building, denotes a dramatic event that occurred in the past, Figs. 17 and 18 .
Even a buttress, added as a protection of the Western wall of the North transept, is a clear sign of some damage that occurred in that area in the past, Fig. 19.

Unfortunately, there are no historical documentations or significant survey data that can testify some collapse or damage in the vaults of the apses.

Fig. 20 indicates all the control nodes of the church model that were monitored during the numerical simulations. The same figure shows the horizontal displacement time history for some meaningful control nodes of the Church along both the longitudinal and transversal directions. In the longitudinal direction a maximum top displacement equal to $6 \mathrm{~cm}$ is computed at the top of the tympanum (control node P1) after about $7 \mathrm{~s}$ from the beginning of the ground motion. The stiffening presence of the internal walls of the narthex has the effect of reducing the out-of-plane rocking of the narthex façade during the application of the accelerograms. The maximum top displacement measured on the top of the narthex façade is about $5.5 \mathrm{~cm}$, a value which is numerically far from the actual deformation level, but which suggests that the out-ofplane rocking of the front of the church could be the result of cumulated damage induced by different seismic sequences over the time (at least 4-5 moderate/high earthquakes occurred in the last 400 years in that area). The evolution of the kinetic and dissipated energy registered during the numerical simulation is shown in Fig. 21. Kinetic energy nullifies at the end of the simulations, 


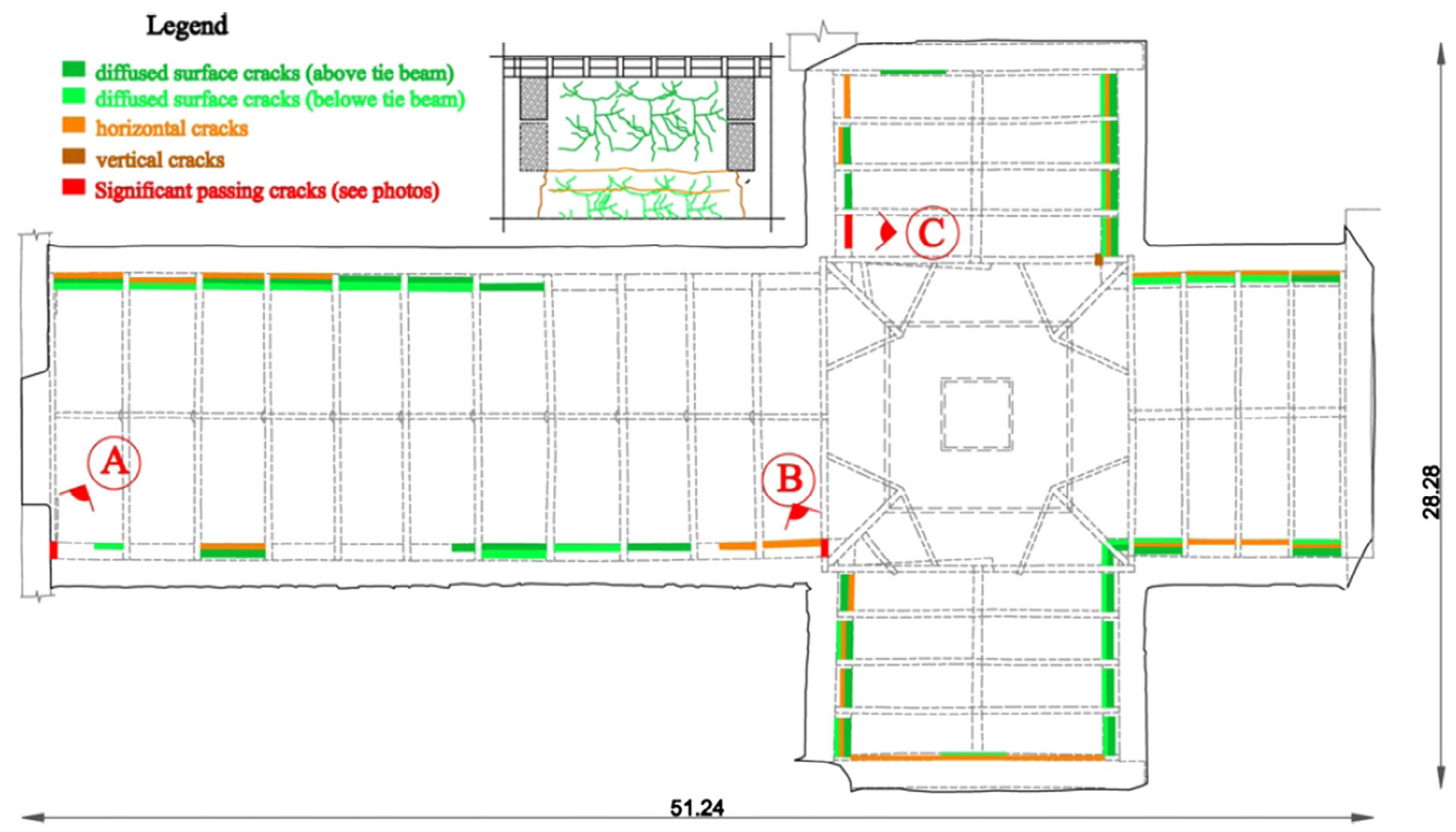

Fig. 14. Vertical cracks at the intersection between the orthogonal walls of the nave and transept.

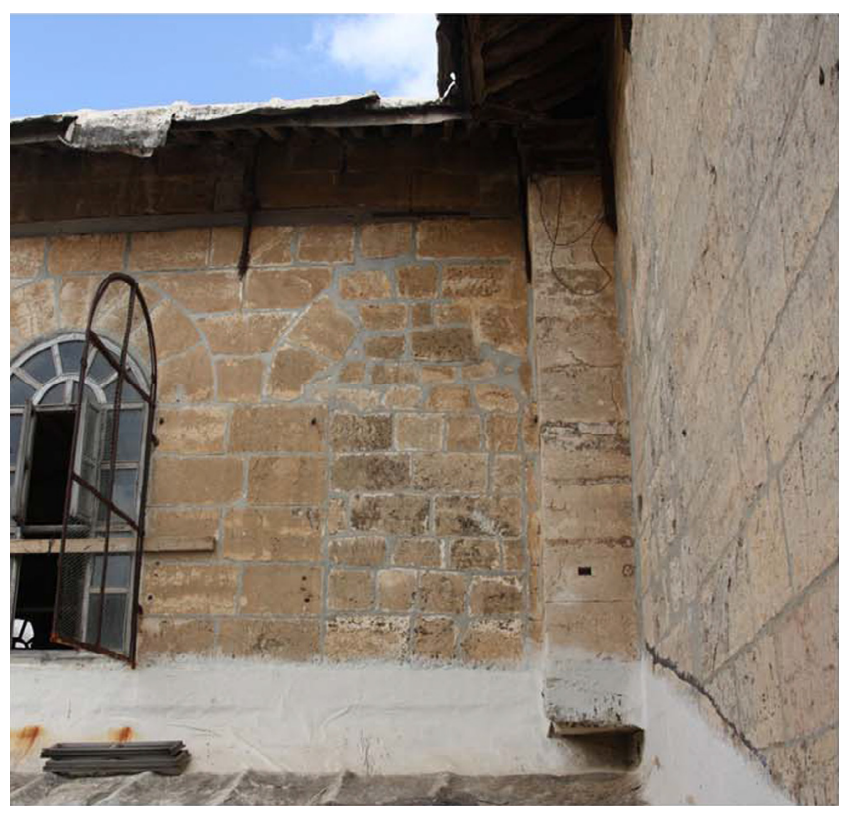

Fig. 15. Buffered window of the nave at the intersection with the transept wall.

meaning that no failure mechanisms form in the model due to the application of the seismic excitation, whereas the dissipated energy is a clear indication that damage cumulates in some parts of the structure.

\section{Non-linear dynamic analyses of the narthex}

The results of the non-linear dynamic analyses performed on the model of the whole Church highlight the vulnerability of the structure under horizontal loads, pointing out some critical regions, which fairly correspond to those observed during the surveys. It is worth noting that the use of sophisticated three- dimensional finite element models requires a large computational effort and the model of the entire Church proved to be very timeconsuming under bidirectional non-linear dynamic analyses. A finite element model of the narthex only was created in order to perform different non-linear dynamic analyses with various peak ground accelerations and obtain a detailed insight into the behavior of such part of the Church. A finer mesh, consisting of about 85,000 tetrahedron elements and depicted in Fig. 25, could be used for the narthex in this model. The internal walls were not modelled in order to reproduce the original configuration of the narthex and because such walls were built at a later time in simple adherence with the others, thus raising doubts on the actual interlocking level between perpendicular walls.

The seismic performance of the narthex was assessed through non-linear dynamic analyses using an artificial accelerogram, with duration equal to $20 \mathrm{~s}$, shown in Fig. 22. For the sake of simplicity, numerical analyses were carried out only in the longitudinal direction. The accelerogram used was generated through the computer code SIMQKE in order to match the Eurocode 8 response spectrum. Different peak ground accelerations ranging between $0.15 \mathrm{~g}$ and $0.25 \mathrm{~g}$ were considered for the analyses.

The finite element model was used to identify the possible different collapse mechanisms that can occur in the narthex. The ground motion applied in the longitudinal direction may cause significant horizontal relative displacements of the narthex façade with respect to the church façade, creating tensile stresses in the vault system. Consequently, the vault system may represent a critical element for the narthex and it is expected to undergo significant damage even at the beginning of the numerical simulation.

Figs. 23 and 24 describe the tensile and compression damage evolution, respectively, during the non-linear dynamic analysis. The results are reported at successive time instants (about $2.2 \mathrm{~s}$, $6.4 \mathrm{~s}, 9.3 \mathrm{~s}$ ) corresponding to the main acceleration peaks of the artificial accelerogram and at the end of the analysis (20 s). It can be noted that damage concentrates mainly in the cross vault system and, to a small extent, on both the façades. In particular, the tensile damage starts along the perimeter of the vault system and then propagates into the middle part involving the whole system. 


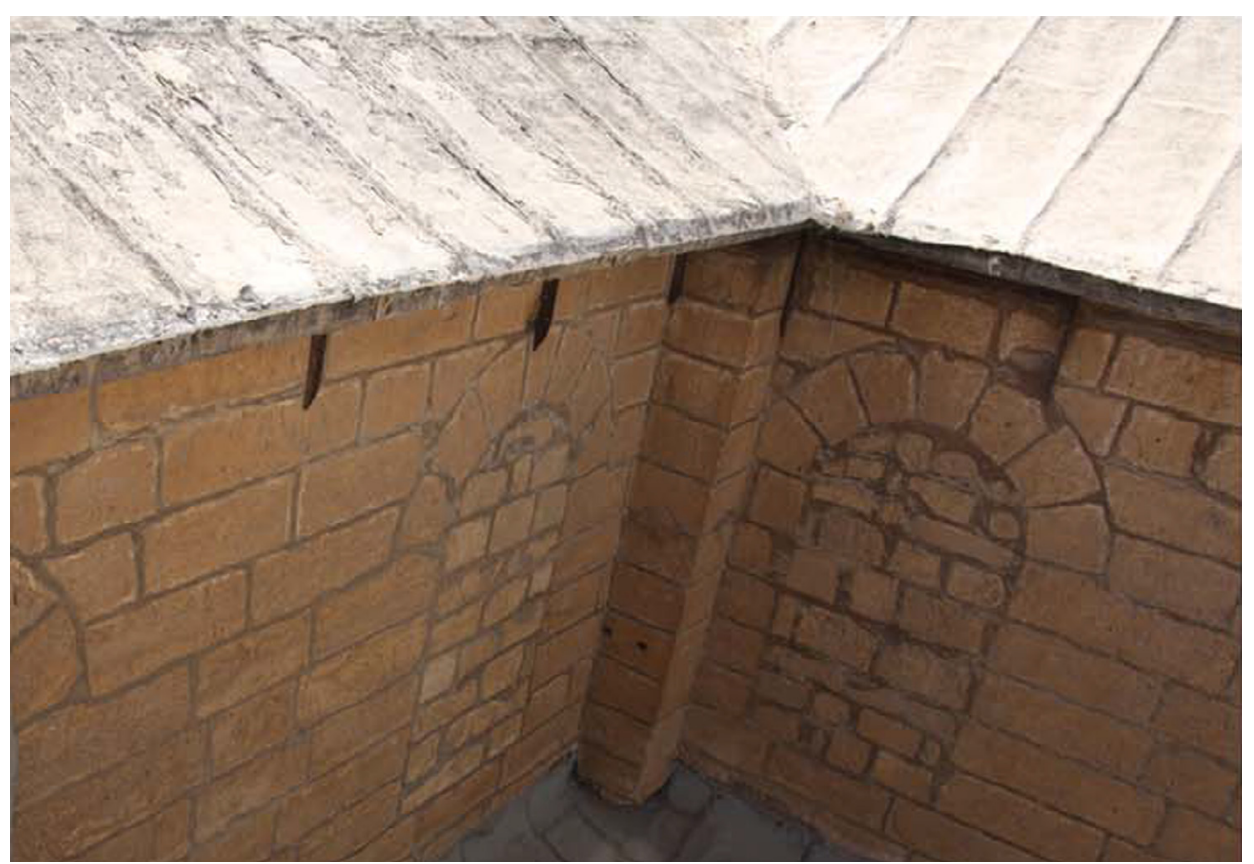

Fig. 16. Buffered windows at the intersection between the apse and transept.

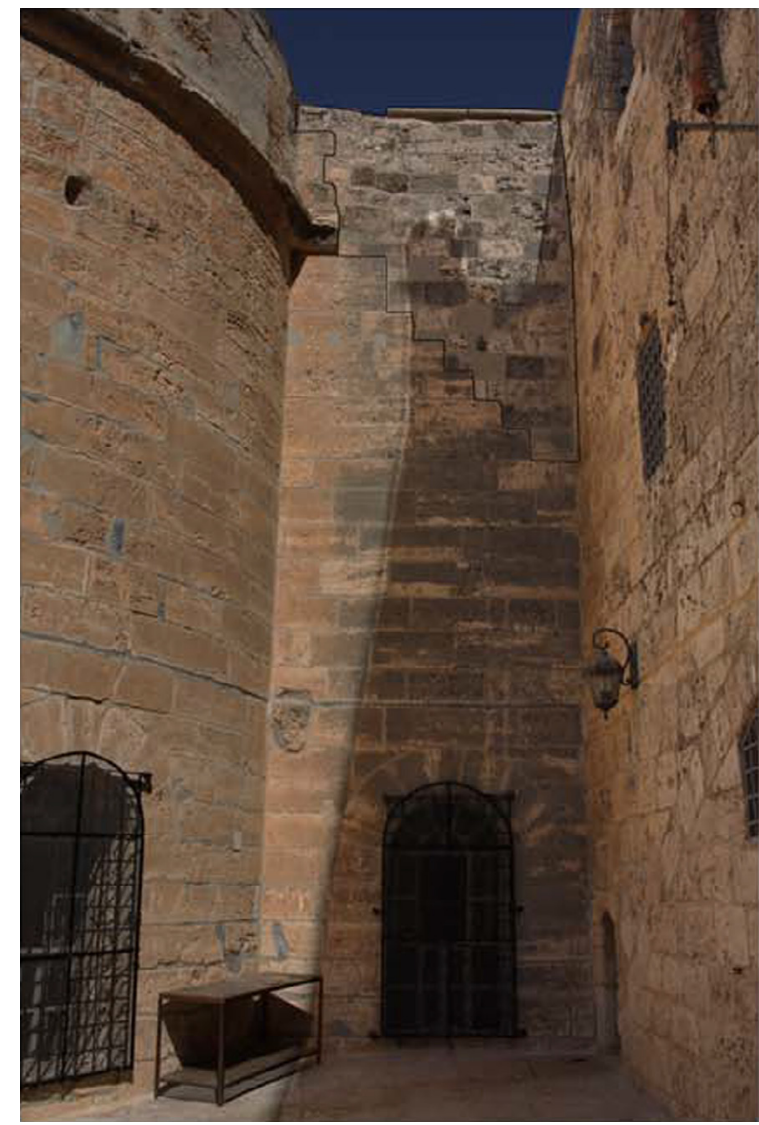

Fig. 17. Re-making in the upper part of the South corner.

On the contrary, the compression damage starts at the top of the vault system and then propagates towards the perimeter. It can be noted that the interlocking of the longitudinal walls with the western façade of the Church tends to experience considerable

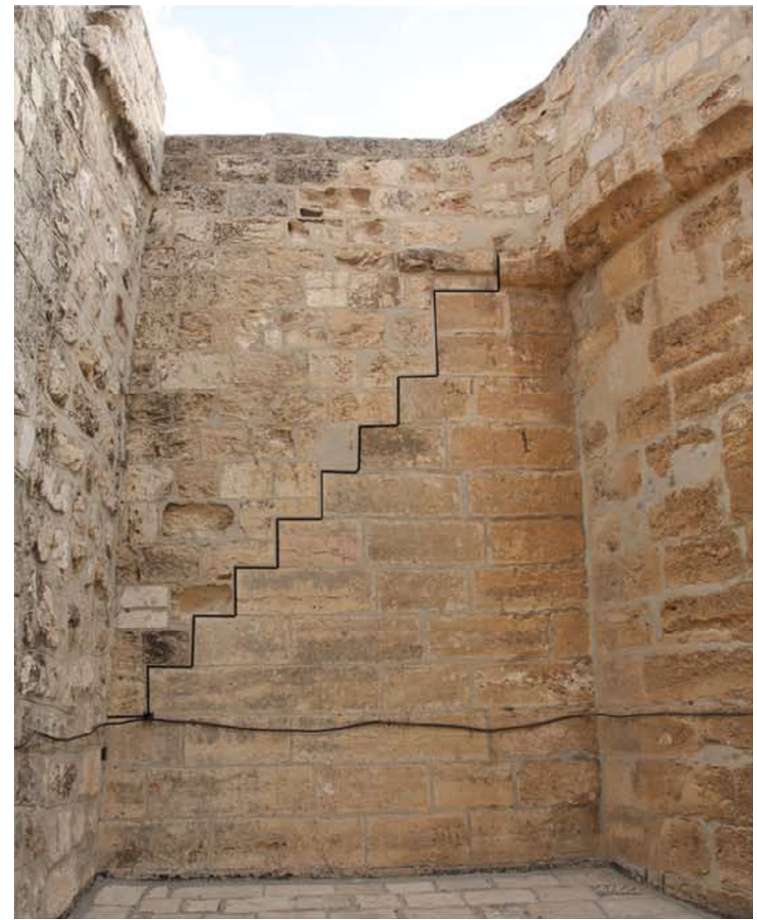

Fig. 18. Re-making of the wall of the North corner.

damage. The results are quite in agreement with the data surveyed, denoting wide detachments along the edges of the vaults, cracks at the extrados close to the perimeter and parallel to the façade, and cracks at the intrados, particularly concentrated in the central part.

Fig. 25 indicates all the control nodes of the narthex model monitored during the numerical simulations. The same figure shows the horizontal and vertical displacement time histories for some meaningful control nodes located on the top of the narthex façade, of the tympanum and of the central and lateral cross vaults. The maximum horizontal displacement (about $10 \mathrm{~cm}$ ) is observed 


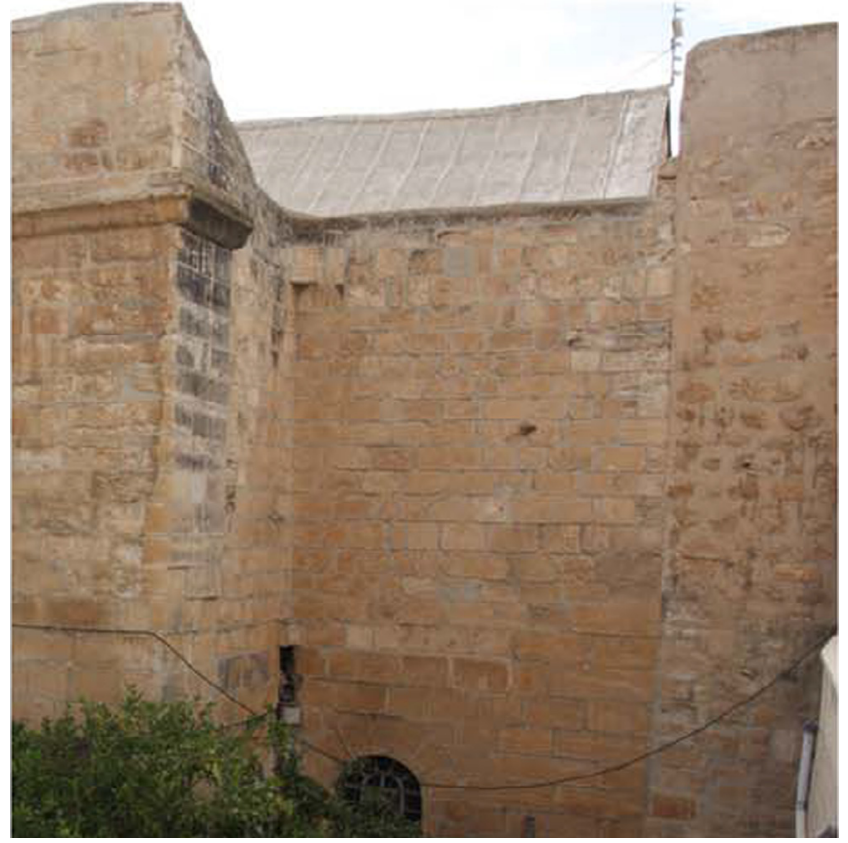

Fig. 19. Buttress added as a protection of the Western wall of the North transept.

for the control node N14 at the top of the tympanum of the main entrance. The narthex façade exhibits a peak horizontal displacement equal to about $6 \mathrm{~cm}$. As regards the vertical displacements, the maximum value, equal to $6 \mathrm{~cm}$, is registered for the central vault.

It is worth noting that both the state of damage and the values of vertical displacements found on the cross vaults through the numerical analyses are in a very good agreement with what was observed in reality, see Fig. 5.
The maximum vertical displacements of the control nodes of the cross vaults are shown in Fig. 26 for different peak ground accelerations. As can be noted, the maximum vertical displacements of the central vault are always larger than those of the other vaults. For high values of seismic intensity levels $\left(a_{g}=0.25 \mathrm{~g}\right)$, the central vault presents a maximum value of vertical displacement equal to about $15 \mathrm{~cm}$.

The maximum values of the horizontal displacement of three meaningful control nodes are shown in Fig. 27 for different peak ground accelerations. It can be noted that the peak values of the horizontal displacement of the narthex façade are always smaller than those of the top of the western façade tympanum. Under a seismic intensity level of $\mathrm{a}_{\mathrm{g}}=0.25 \mathrm{~g}$ the tympanum exhibits peak displacements equal to about $35 \mathrm{~cm}$, whereas the maximum displacement registered for the narthex façade is about $20 \mathrm{~cm}$.

Non-linear dynamic analyses are able to provide, among other information, the residual displacements of the control nodes. Residual displacements are the permanent deformations of a structure that remain at the end of a seismic excitation. From the displacement time-history of a selected node, it can be deduced if significant residual displacements are present at the end of the numerical simulation. Typically, residual displacements are significantly lower than maximum displacements, but they can achieve significant values in the case of considerable damage. Moreover, large residual displacements can provide useful information on the damage level of the structure. Fig. 28 shows the maximum residual displacements computed at the end of the numerical simulations for different ground motion intensities. The maximum values of the residual displacements $(35 \mathrm{~cm})$ are registered for the western façade of the Church when subjected to seismic excitation with $\mathrm{a}_{\mathrm{g}}=0.25 \mathrm{~g}$. As can be observed, the residual displacement found for the narthex façade is about $20 \mathrm{~cm}$, still lower than the real ones, but indicating that a seismic event may be the cause of the present state of degradation. Probably, larger residual displacements might be achieved by simulating the occurrence of a sequence of ground motions, as confirmed by the chronicles of the earthquakes in that area.

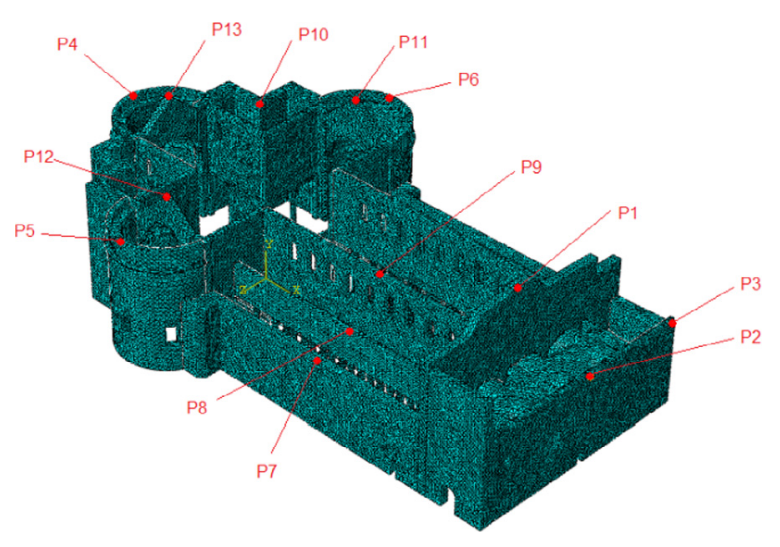

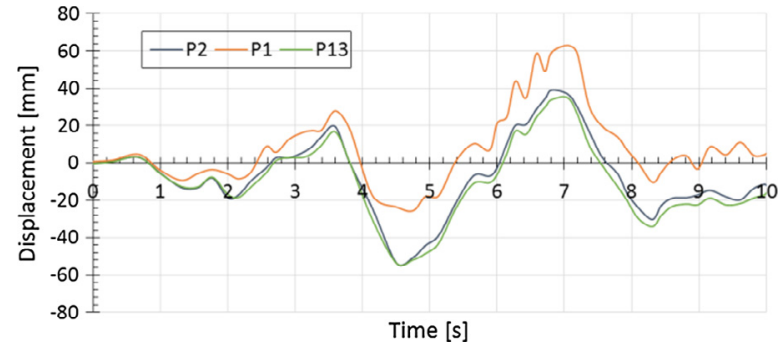

Longitudinal direction

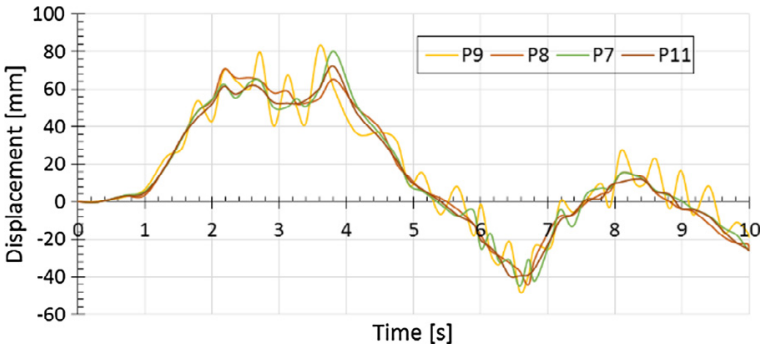

Transversal direction

Fig. 20. Displacement time history of some control nodes along the longitudinal and transversal directions during the non-linear dynamic analysis. 

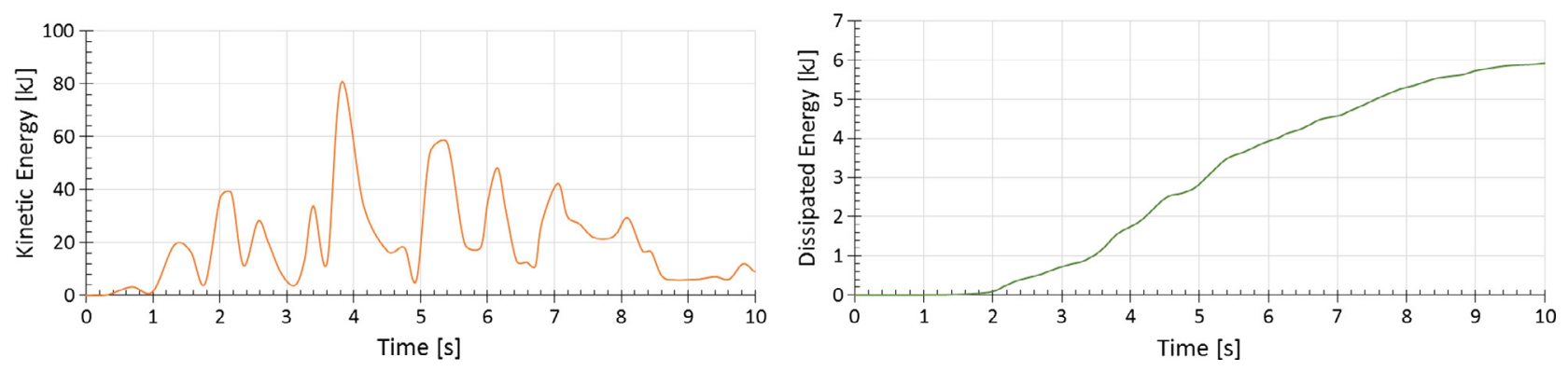

Fig. 21. Kinetic and dissipated energy time history diagrams.

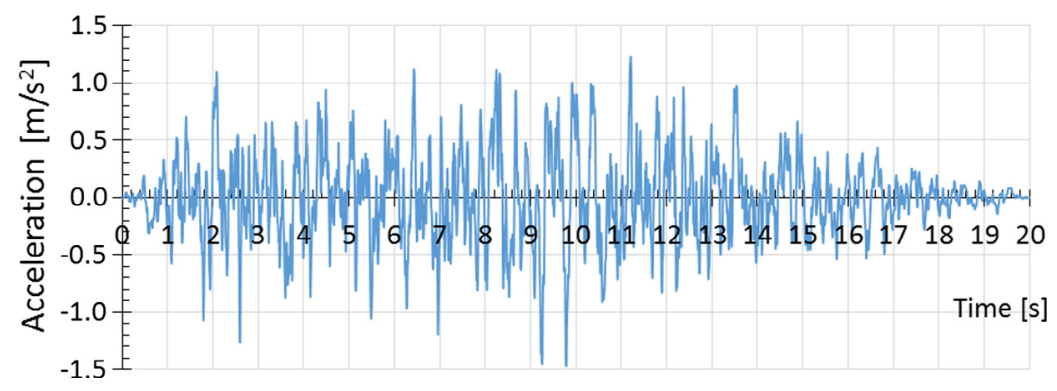

Fig. 22. Artificial accelerogram used for the non-linear dynamic analyses of the narthex.

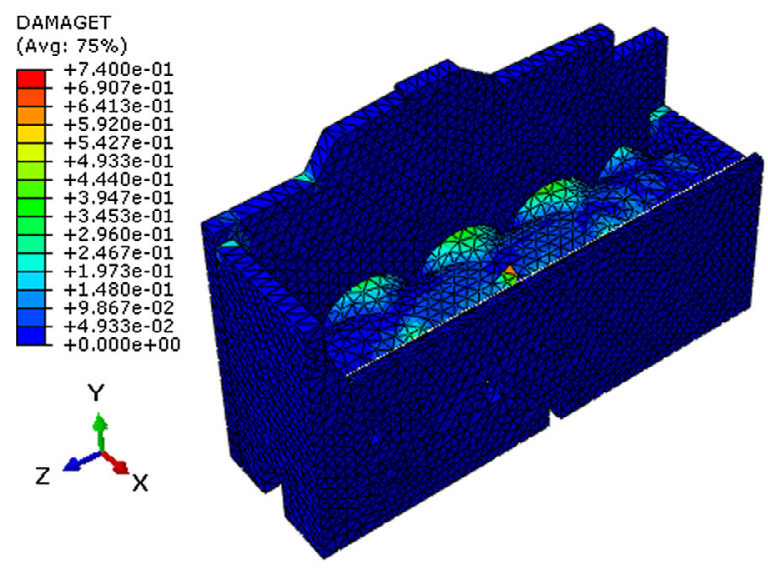

$$
\mathrm{t}=2.2 \mathrm{~s}
$$

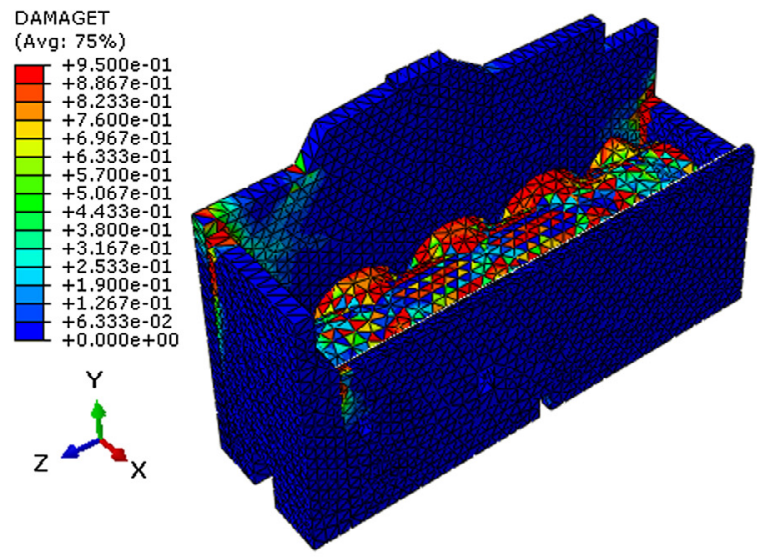

$$
\mathrm{t}=9.3 \mathrm{~s}
$$
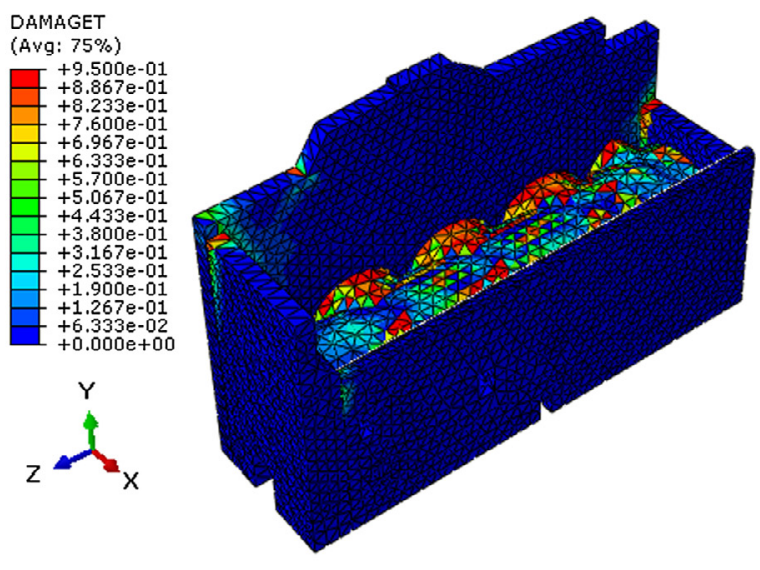

$$
\mathrm{t}=6.4 \mathrm{~s}
$$
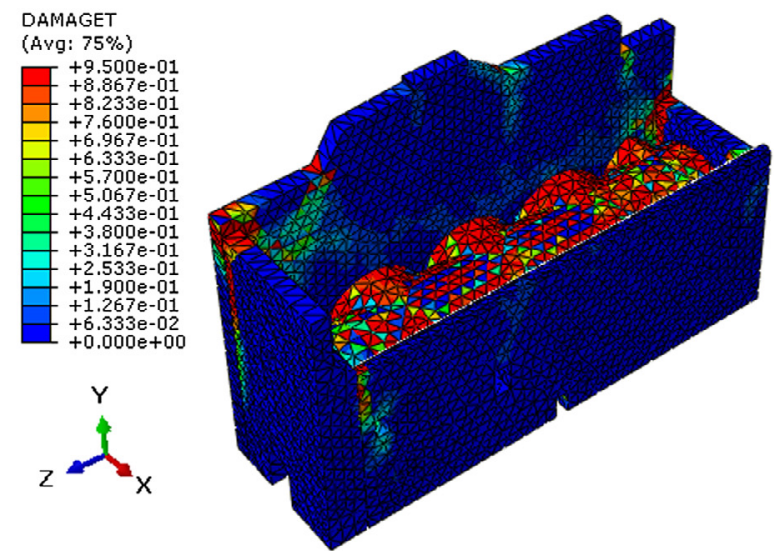

$\mathrm{t}=20 \mathrm{~s}$

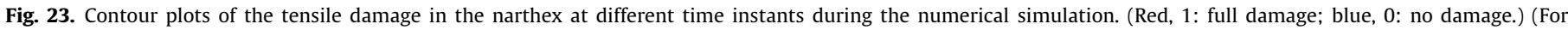
interpretation of the references to colour in this figure legend, the reader is referred to the web version of this article.) 

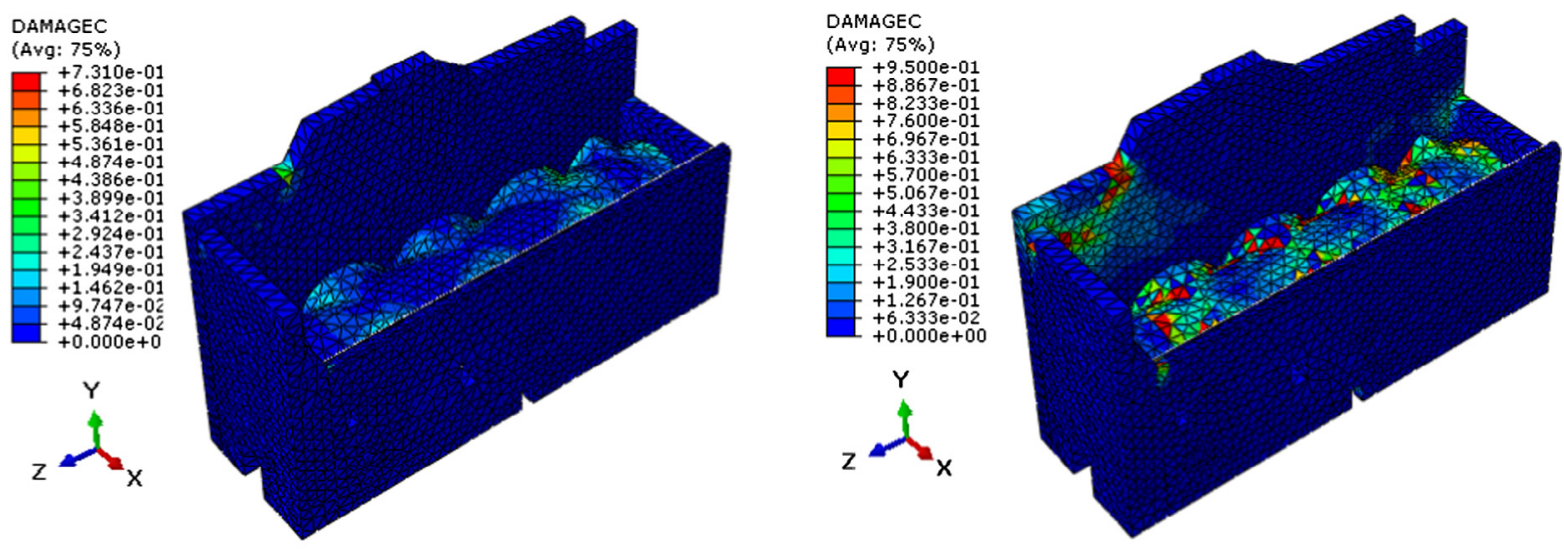

$\mathrm{t}=2.2 \mathrm{~s}$

$$
\mathrm{t}=6.4 \mathrm{~s}
$$
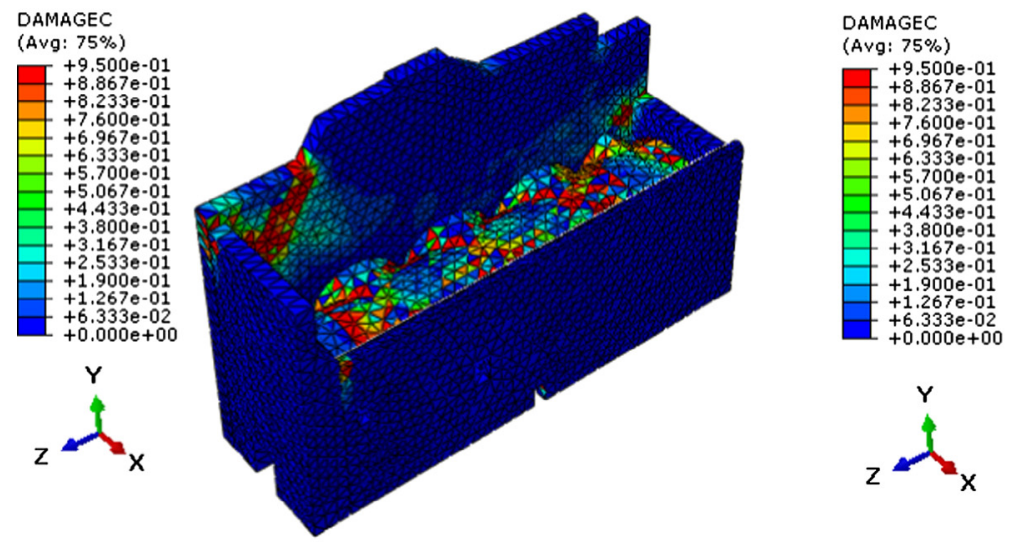

$\mathrm{t}=9.3 \mathrm{~s}$

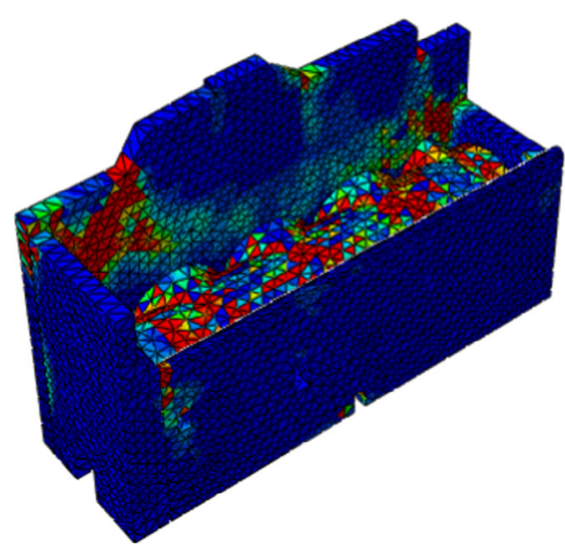

$\mathrm{t}=20 \mathrm{~s}$

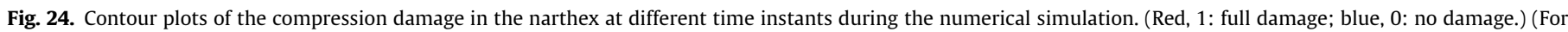
interpretation of the references to colour in this figure legend, the reader is referred to the web version of this article.)

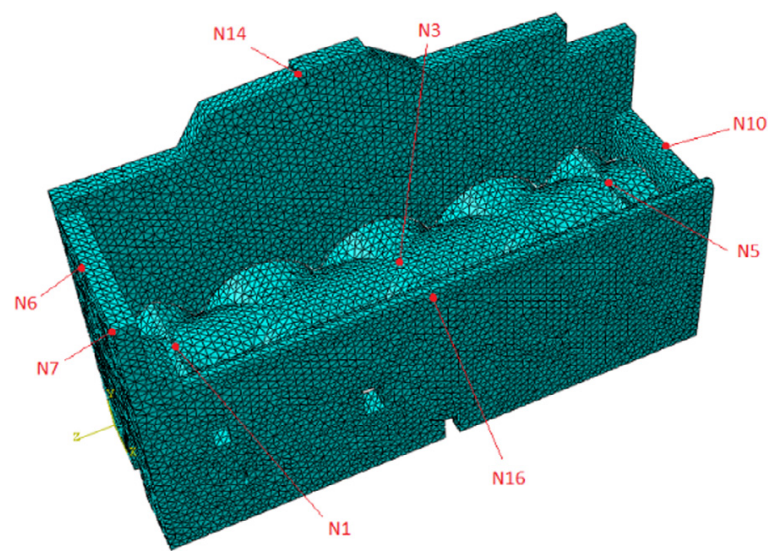

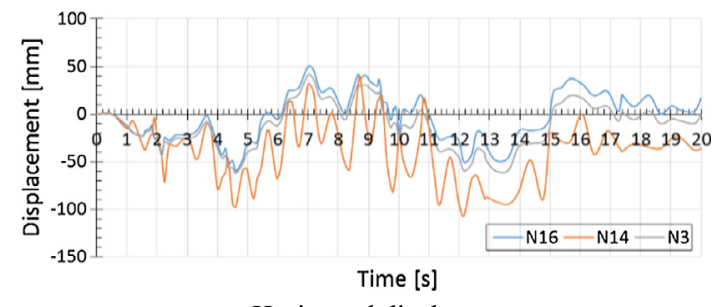

Horizontal displacement

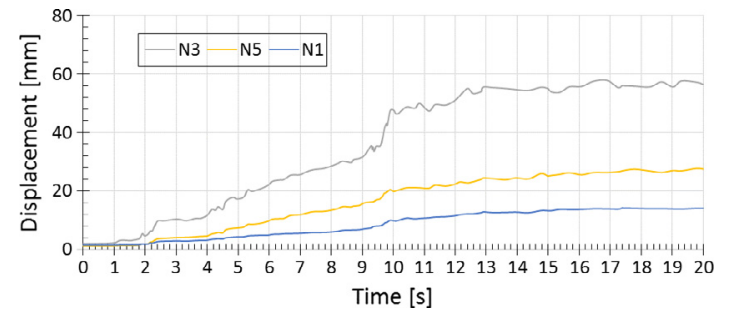

Vertical displacement

Fig. 25. Displacement time-history of some control nodes during the non-linear dynamic analysis. 


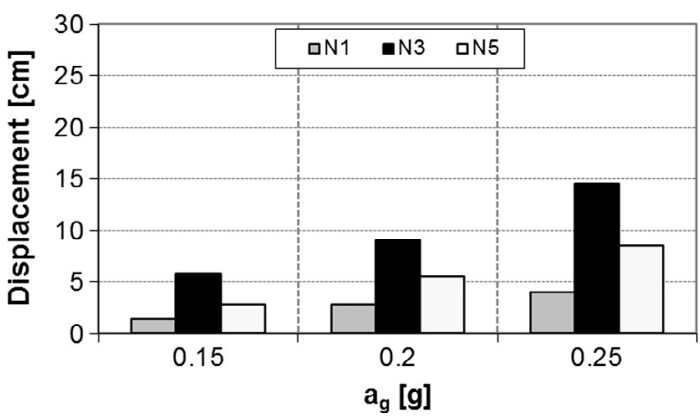

Fig. 26. Maximum vertical displacements of some control nodes for different peak ground accelerations.

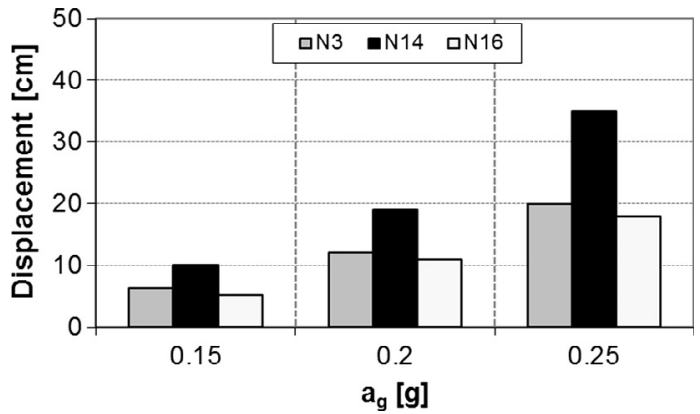

Fig. 27. Maximum values of the horizontal displacement of some control nodes for different peak ground accelerations.

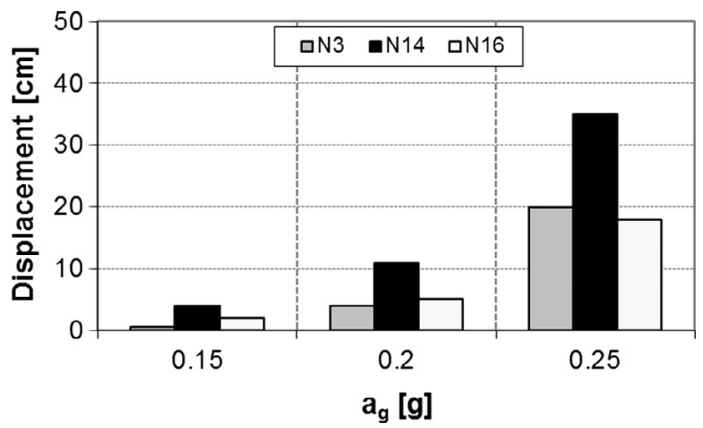

Fig. 28. Residual horizontal displacements of some control nodes for different peak ground accelerations.

\section{Conclusions}

This study summarizes some results obtained through a wide numerical investigation carried out on the Nativity Church in Bethlehem, with particular reference to the narthex. Advanced finite element models, accounting for masonry damage and softening, have been analyzed through non-linear dynamic simulations with different intensity levels in order to identify the possible causes of damage in the narthex and the whole Church.

Bidirectional non-linear dynamic analyses were first performed on the model of the entire Church, reproducing the probable configuration of the Church at the beginning of the Crusader period and soon after the replacement of the timber roof with a masonry cross vault system. From an overall analysis of the numerical results, it is possible to notice that the Church exhibits damage for the seismic excitation expected in that region. It is evident that damage spreads very quickly in the vault system, in the semidomes and near the interlocking of the orthogonal walls. The damage in the vaults starts in the lateral right corner and then propagates towards the middle.
Then, the narthex was separated from the Church and was analyzed under different levels of seismic excitation applied only in the longitudinal direction. Numerical results show that the behavior of the narthex is considerably affected by the presence of the vaults that act as connecting element between the western façade of the Church and the façade of the narthex. During a moderate intensity earthquake, the vault system is subjected to significant stresses and consequently to severe damage. The second critical element of the narthex is the western façade that tends to show a local overturning mechanism due to the gradual accumulation of damage near the base of the vault system. Moreover, the façade of the narthex can reach significant displacements under seismic excitation with $\mathrm{a}_{\mathrm{g}}=0.25 \mathrm{~g}$. The results seem to indicate that the rotation of the narthex façade, with a consequent maximum outof-plane displacement of about $40 \mathrm{~cm}$, may be probably due to a seismic event of great intensity or to several moderate seismic events that occurred in sequence over the time. It is worth mentioning that results closer to the measured data can be obtained by assuming a sequence of ground motions, as documented by some historical records, and proper unilateral contact conditions at the interface between vaults and façade walls.

\section{Acknowledgements}

Thanks are due to Piacenti S.p.A., main Contractor of the restoration works in the Church of the Nativity, and to all his staff for providing some technical information.

One of the Authors, C. Alessandri, is especially grateful to the Palestinian Presidential Committee of the Church of the Nativity for being appointed as general consultant for the ongoing restoration works and being able to give his contribution to the studies on the Church.

\section{References}

[1] Hamilton RW. Excavations in the Atrium of the Church of the Nativity. Q Depart Antiq Palestine 1934;3:1-8.

[2] Harvey W. Recent discoveries at the Church of the Nativity, Bethlehem. Archaeologia 1938;87:7-17.

[3] Amico Fra Bernardino (1609). Trattato delle piante et imagini dei sacri edificii di Terra Santa. Jerusalem: Franciscan Press; 1953.

[4] Bacci M, Bianchi G, Campana S, Fichera G. Historical and archaeological analysis of the Church of the Nativity. J Cult Herit 2012;13:5-26.

[5] Milani G, Del Grosso A, Alessandri C, Valente M. A non-linear finite element approach to predict the structural damage of the Narthex of the Bethlehem Nativity Church. In: Kruis J, Tsompanakis Y, Topping BHV (editors). Proceedings of the fifteenth international conference on civil, structural and environmental engineering computing, Civil-Comp Press, Stirlingshire, UK, Paper 58; 2015. http://dx.doi.org/10.4203/ccp.108.58.

[6] Alessandri C, Mallardo V. Structural assessments of the Church of the Nativity in Bethlehem. J Cult Herit 2012;13:61-9.

[7] ABAQUS ${ }^{\circledR}$, theory manual, version 6.14 .

[8] Parisi F, Augenti N. Earthquake damages to cultural heritage constructions and simplified assessment of artworks. Eng Fail Anal 2013;34:735-60.

[9] Brandonisio G, Lucibello G, Mele E, De Luca A. Damage and performance evaluation of masonry churches in the 2009 L'Aquila earthquake. Eng Fail Anal 2013;34:693-714.

[10] Brandonisio G, Mele E, De Luca A. Closed form solution for predicting the horizontal capacity of masonry portal frames through limit analysis and comparison with experimental test results. Eng Fail Anal 2015;55:246-70.

[11] Foraboschi P. Church of San Giuliano di Puglia: seismic repair and upgrading. Eng Fail Anal 2013;33:281-314.

[12] Bartoli G, Betti M. Cappella dei Principi in Firenze, Italy: experimental analyses and numerical modeling for the investigation of a local failure. J Perform Constr Facil 2013:27(1):4-26.

[13] Betti M, Bartoli G, Orlando M. Evaluation study on structural fault of a Renaissance Italian palace. Eng Struct 2010;32(7):1801-13.

[14] Barbieri G, Valente M, Biolzi L, Togliani C, Fregonese L, Stanga G. An insight in the late Baroque architecture: an integrated approach for a unique Bibiena church. J Cult Herit 2017;23:58-67.

[15] Pieraccini M, Dei D, Betti M, Bartoli G, Tucci G, Guardini N. Dynamic identification of historic masonry towers through an expeditious and nocontact approach: application to the "Torre del Mangia" in Siena (Italy). J Cult Herit 2014;15(3):275-82. 
[16] Lagomarsino S, Resemini S. The assessment of damage limitation state in the seismic analysis of monumental buildings. Earthq Spectra 2009;25(2):323-46.

[17] Milani G, Valente M. Comparative pushover and limit analyses on seven masonry churches damaged by the 2012 Emilia-Romagna (Italy) seismic events: possibilities of non-linear Finite Elements compared with pre-assigned failure mechanisms. Eng Fail Anal 2015;47:129-61.

[18] Milani G, Valente M. Failure analysis of seven masonry churches severely damaged during the 2012 Emilia-Romagna (Italy) earthquake: non-linear dynamic analyses vs conventional static approaches. Eng Fail Anal 2015;54:13-56.

[19] Milani G, Venturini G. Automatic fragility curve evaluation of masonry churches accounting for partial collapses by means of 3D FE homogenized limit analysis. Comput Struct 2011;89:1628-48.

[20] Milani G, Venturini G. Safety assessment of four masonry churches by a plate and shell FE non-linear approach. J Perform Constr Facil 2013;27(1):27-42.

[21] Valente M, Barbieri G, Biolzi L. Damage assessment of three medieval churches after the 2012 Emilia earthquake. Bull Earthq Eng 2012;2017. http://dx.doi. org/10.1007/s10518-016-0073-7.

[22] Milani G. Lesson learned after the Emilia Romagna, Italy, 20-29 May 2012 earthquakes: a limit analysis insight on three masonry churches. Eng Fail Anal 2013;34:761-78.

[23] Comité Européen de Normalisation. Eurocode 8 EN1998-1 and EN1998-3: design of structures for earthquake resistance. Brussels: CEN; 2004.

[24] DM 14/01/2008. Nuove norme tecniche per le costruzioni. Ministero delle Infrastrutture (GU n.29 04/02/2008), Rome, Italy [New technical norms on constructions].

[25] Circolare $n^{\circ} 617$ del 2 febbraio 2009. Istruzioni per l'applicazione delle nuove norme tecniche per le costruzioni di cui al decreto ministeriale 14 gennaio;
2008 [Instructions for the application of the new technical norms on constructions].

[26] DPCM 9/2/2011. Linee guida per la valutazione e la riduzione del rischio sismico del patrimonio culturale con riferimento alle Norme tecniche delle costruzioni di cui al decreto del Ministero delle Infrastrutture e dei trasporti del 14 gennaio; 2008 [Italian guidelines for the evaluation and the reduction of the seismic risk for the built heritage, with reference to the Italian norm of constructions].

[27] Page AW. The biaxial compressive strength of brick masonry. Proc Inst Civ Eng 1981;71(Part 2):893-906.

[28] Milani G, Lourenco PB, Tralli A. Homogenised limit analysis of masonry walls. Part I: failure surfaces. Comput Struct 2006:84(3-4):166-80.

[29] Milani G, Lourenço PB, Tralli A. Homogenised limit analysis of masonry walls. Part II: structural examples. Comput Struct 2006;84:181-95.

[30] Milani G, Lourenço PB, Tralli A. A homogenization approach for the limit analysis of out-of-plane loaded masonry walls. I Struct Eng ASCE 2006;132 (10):1650-63.

[31] Lubliner J, Oliver J, Oller S, Oñate E. A plastic-damage model for concrete. Int J Solids Struct 1989;25:299-326.

[32] Lee J, Fenves GL. Plastic-damage model for cyclic loading of concrete structures. J Eng Mech 1998;124:892-900.

[33] Valente M, Milani G. Non-linear dynamic and static analyses on eight historical masonry towers in the North-East of Italy. Eng Struct 2016;114:241-70

[34] Van Der Pluijm R. Shear Behaviour of bed joints. In: Proceedings of 6th North American masonry conference, Philadelphia, 6-9 June 1993. p. 125-36.

[35] Valente M, Milani G. Seismic assessment of historical masonry towers by means of simplified approaches and standard FEM. Constr Build Mater 2016;108:74-104. 